\title{
A model of the three-dimensional evolution of Arctic melt ponds on first-year and multiyear sea ice
}

\author{
F. Scott ${ }^{1}$ and D. L. Feltham ${ }^{1,2}$ \\ Received 27 January 2010; revised 15 July 2010; accepted 20 September 2010; published 28 December 2010.
}

[1] During winter the ocean surface in polar regions freezes over to form sea ice. In the summer the upper layers of sea ice and snow melts producing meltwater that accumulates in Arctic melt ponds on the surface of sea ice. An accurate estimate of the fraction of the sea ice surface covered in melt ponds is essential for a realistic estimate of the albedo for global climate models. We present a melt-pond-sea-ice model that simulates the three-dimensional evolution of melt ponds on an Arctic sea ice surface. The advancements of this model compared to previous models are the inclusion of snow topography; meltwater transport rates are calculated from hydraulic gradients and ice permeability; and the incorporation of a detailed one-dimensional, thermodynamic radiative balance. Results of model runs simulating first-year and multiyear sea ice are presented. Model results show good agreement with observations, with duration of pond coverage, pond area, and ice ablation comparing well for both the first-year ice and multiyear ice cases. We investigate the sensitivity of the melt pond cover to changes in ice topography, snow topography, and vertical ice permeability. Snow was found to have an important impact mainly at the start of the melt season, whereas initial ice topography strongly controlled pond size and pond fraction throughout the melt season. A reduction in ice permeability allowed surface flooding of relatively flat, first-year ice but had little impact on the pond coverage of rougher, multiyear ice. We discuss our results, including model shortcomings and areas of experimental uncertainty.

Citation: Scott, F., and D. L. Feltham (2010), A model of the three-dimensional evolution of Arctic melt ponds on first-year and multiyear sea ice, J. Geophys. Res., 115, C12064, doi:10.1029/2010JC006156.

\section{Introduction}

[2] The rate of decline of Arctic summer sea ice extent has increased dramatically in recent years. A record minimum of ice extent was recorded in 2007, beating the previous record minimum in 2005. The 2007 extent minimum was almost matched again in 2008. The decrease in sea ice area has been accompanied by a decrease in sea ice volume. For instance, Rothrock et al. [1999] observed a 40\% reduction in average ice thickness by analyzing submarine measurements of sea ice draft from the 1970s and 1990s. Wider area estimates of sea ice thickness, based on satellite altimetry [Laxon et al., 2003; Giles et al., 2008], also reveal a reduction in ice thickness.

[3] Global warming is intensified in polar regions due to the albedo feedback mechanism [e.g., Ebert et al., 1995] and, as a result of this, Arctic sea ice is a sensitive indicator of climate change, as well as being an important climate component. Climate prediction studies using Global Climate

\footnotetext{
${ }^{1}$ Centre for Polar Observation and Modelling, Department of Earth Sciences, University College London, London, UK.

${ }^{2}$ British Antarctic Survey, Cambridge, UK.

Copyright 2010 by the American Geophysical Union. 0148-0227/10/2010JC006156
}

Models (GCMs), such as the Intergovernmental Panel on Climate Change AR4 study, are unable to simulate the observed rapid reduction of sea ice extent [Solomon et al., 2007]. The inability of GCMs to simulate the rapid reduction in Arctic summer sea ice extent, combined with satellite and field observations demonstrating the importance of sea ice melt, indicate the need for a more realistic representation of sea ice melt processes. In particular, GCMs do not model melt ponds on sea ice. As the melt season progresses, part of the surface meltwater produced accumulates to form melt ponds that cover an increasing fraction of the surface, reaching around $50 \%$ at the end of the melt season.

[4] Melt ponds are a persistent feature of the summertime sea ice surface in the Arctic [Derksen et al., 1997; Fetterer and Untersteiner, 1998; Tucker et al., 1999; Yackel et al., 2000; Tschudi et al., 2001]. Melt ponds have a significant impact on the both the albedo of sea ice and the amount of sea ice melt. The albedo of pond-covered ice is variable and has been measured in field experiments to be between 0.1 and 0.5 [e.g., Perovich et al., 2002b; Eicken et al., 2004]. These albedo values are much lower than bare ice and snow-covered ice, which are relatively stable at $0.6-0.65$ and 0.84-0.87 [Perovich, 1996]. Since the ice concentration in the interior Arctic is greater than $85 \%$, melt ponds contribute significantly to the area-averaged albedo, with an 


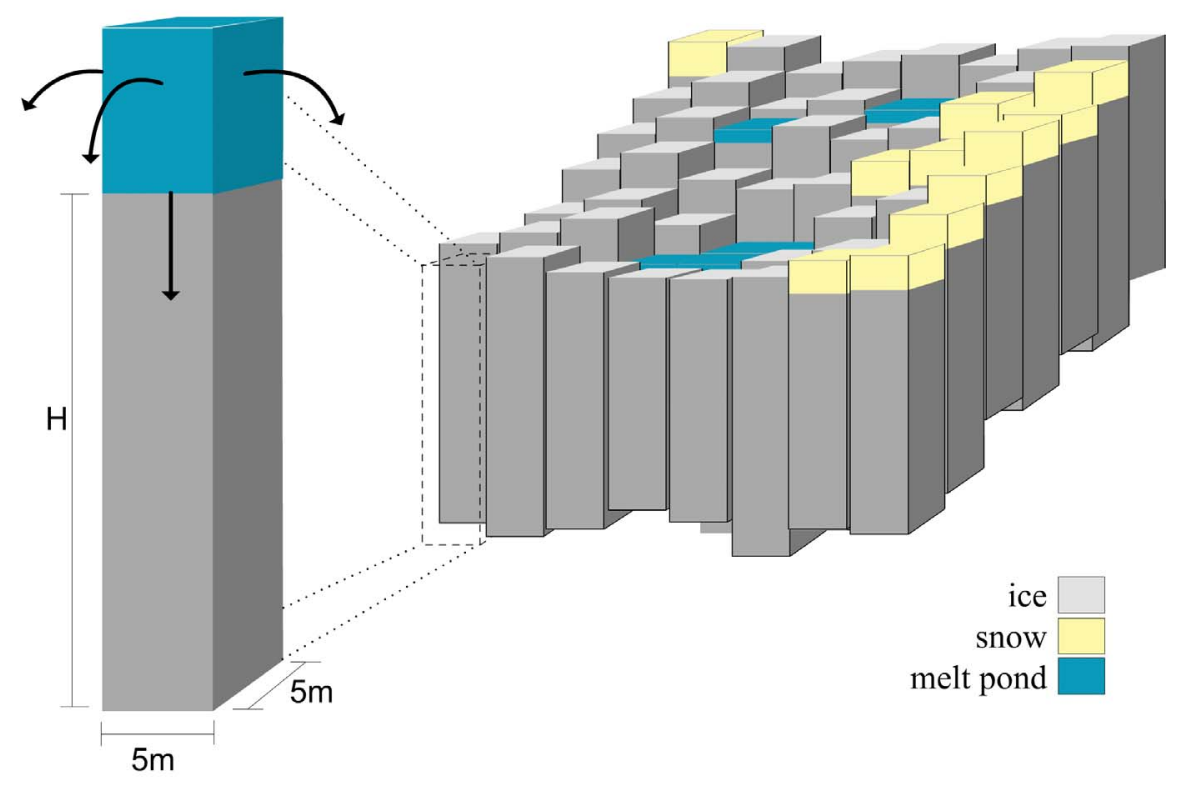

Figure 1. A schematic diagram of the cellular automaton. Each cell has an individual ice thickness, H, and has a horizontal surface area of $25 \mathrm{~m}^{2}$. Melting decreases the ice thickness in a cell and allows a pond to form on the surface. Water can drain through a cell or can be transported to adjacent cells.

approximately linear decrease in albedo with increasing pond fraction [Eicken et al., 2004]. For example, an uncertainty in pond fraction of $15 \%$ over the entire Arctic Ocean is equivalent to an uncertainty of $10 \%$ in the total ice area in the calculation of mean Arctic Ocean albedo.

[5] Melt pond parameterizations that can be incorporated into GCMs are now being developed [Flocco and Feltham, 2007; Pedersen et al., 2009; Flocco et al., 2010], however, to ensure that parameterizations are realistic we need to understand the physics that govern melt pond evolution so that the parameterizations can be physically based.

[6] Our objective here is to create a model of melt pond evolution on sea ice, based on the physics believed to govern pond formation and growth, that can be used to determine the sensitivity of melt ponds to ice and snow surface topography and uncertainty in sea ice permeability, and thus improve our understanding of the evolution of melt ponds. Our model uses the cellular automaton concept described by Lüthje et al. [2006], with significant improvements described below, and the one-dimensional, vertical heat transport model described by Taylor and Feltham [2004]. In the model the ice cover is represented by a horizontal square grid of cells like a checker board and each cell contains a column of ice, which may have a melt pond or snow cover, see Figure 1.

[7] The initial ice and snow topographies have been generated using standard statistical methods so that firstyear and multiyear ice can be modeled using the statistical properties of necessarily limited observations. Ice surface and base heights are generated separately leading to a surface topography with some ice surface heights below sea level initially. The initial surface topography in the Lüthje et al. [2006] model is based on ice freeboard measurements and all cells have positive initial freeboard.

[8] In our model the entire floe is in hydrostatic equilibrium, but not necessarily every cell, and sea level with respect to the floe is recalculated every time step. This allows vertical drainage to be realistically modeled using Darcy's law, rather than take place at a fixed rate as in the Lüthje et al. [2006] model. Horizontal water transport rates in our model vary from cell to cell depending on the solid fraction in the ice. Therefore in the model described in this paper there is spatial as well as temporal variation in drainage rate.

[9] The ice and snow melt rates in our model are calculated from the detailed thermal and radiative balances described by Taylor and Feltham [2004]. In the [Lüthje et al., 2006] model bare ice melts at a fixed rate and melting beneath ponds take place at an enhanced rate using an ad hoc algorithm motivated by observations. There is no basal melting in the Lüthje et al. [2006] model and there is no separate representation of snow cover.

[10] In section 2 we present the melt-pond-sea-ice model including the model of meltwater transport, an explanation of how the cellular approach is combined with the onedimensional thermodynamic model, and a description of the construction of initial ice and snow topographies. In section 3 we present the results of two model runs that simulate the evolution of melt ponds on first-year ice and multiyear ice, which are compared with field data and the results of Lüthje et al. [2006]. In section 4 we present sensitivity studies for both first-year and multiyear sea ice in which we vary the initial snow cover (depth and roughness), ice topography (roughness), and vertical ice permeability, and compare 
these studies with observations. Finally, in section 5, we summarize our results and state our main conclusions.

\section{Model Description}

[11] The automaton grid consists of cells that evolve largely independently of each other, interacting through the transport of water between cells, see Figure 1. Each cell represents a $5 \mathrm{~m} \times 5 \mathrm{~m}$ square area of sea ice and, within this area, ice thickness, meltwater depth and snow cover are assumed to be uniform. The entire grid represents an $200 \mathrm{~m}$ $\times 200 \mathrm{~m}$ area of a sea ice floe (40 cells per side). The area is constrained to this size so that it can represent an arbitrary section of a sea ice floe without the complication of having to take edge effects into consideration. The boundaries are periodic so that meltwater transported out of one edge cell is transported back into the opposite edge cell. A time step of the model consists of the following five stages:

[12] 1. One-dimensional thermodynamic equations following Taylor and Feltham [2004] are solved in the vertical direction in every cell to calculate the heat flux through ice, snow and meltwater (if it exists). These calculations establish the albedo, volume of meltwater produced, basal ablation and the saturation of snow on a cell by cell basis.

[13] 2. Sea level with respect to the floe is established and used to calculate the hydraulic head in each cell.

[14] 3. Water is driven between adjacent cells by differences in hydraulic head between the cells. The volume of horizontal water transport is calculated using Darcy's law for flow through a porous medium.

[15] 4. Vertical drainage through the ice in each cell is calculated using Darcy's law and the hydraulic head.

[16] 5. The volume of water transported into and out of the cells is updated and one cycle of the automaton model is complete.

[17] Note the choice of the order of operation of (2)-(4), which corresponds to the rapidity of the relevant physical processes, is needed in order to calculate meltwater transport accurately for all practical choices of model time step (i.e., greater than about a minute). We used a model time step of $1 \mathrm{~h}$.

[18] Each cell in the cellular model calls a separate onedimensional thermodynamic model, as described by Taylor and Feltham [2004]. The thermodynamic model model is run at a lower vertical spatial and temporal resolution than that by Taylor and Feltham [2004] (20 grid points and time steps of $1 \mathrm{~h}$, compared with 641 grid points and time steps of 600 seconds in the original model runs), first due to time constraints, to allow a model run to be completed on a typical workstation in just over a week, and secondly to ensure that the cellular automaton and thermodynamic models are of comparable accuracy. The resolution of the thermodynamic model was tested in isolation from the cellular model to ensure that the lower-resolution results were not significantly different from higher-resolution results. The relatively coarse grid length of $5 \mathrm{~m}$ was chosen because this is the average distance water is expected to travel in a time step length of $1 \mathrm{~h}$. A higher spatial (and temporal) resolution calculation was found to have no substantial impact on the results.

[19] We describe the melt-pond-sea-ice model in the following sections: section 2.1 describes the calculation of meltwater transport and drainage, section 2.2 briefly describes the thermodynamic and radiative model used to calculate melt rates, and section 2.3 describes the generation of the sea ice and snow topographies.

\subsection{Calculation of Meltwater Transport and Drainage}

[20] The surface of sea ice is deformed by mechanical processes such as ridging, or thermodynamic processes such as the formation and drainage of melt ponds and the freezing over of partially drained ponds [Fetterer and Untersteiner, 1998] and therefore in places the sea ice surface is likely to have a negative freeboard. In this model the entire floe/ computational domain is in hydrostatic equilibrium but not individual cells. Sea level with respect to the floe is established initially using the assumption that the entire floe is in hydrostatic equilibrium and is then updated as mass is removed from the surface and base of the ice.

[21] Mean draft, $D$, is calculated every time step from

$$
D=\frac{\sum\left(x_{i}+x_{s}+x_{p}\right)}{\rho A}
$$

where $x$ is the mass of ice, snow and water in each cell, where index $i$ represents ice, $s$ represents snow, and $p$ represents melt pond, $\rho$ is ocean density, and $A$ is total floe area.

[22] The area covered in melt ponds is affected by horizontal and vertical water transport [Eicken et al., 2002]. In this model water can be removed from the grid by vertical drainage and can be transported between cells, depending on differences in hydraulic head between cells. We model vertical and horizontal water transport in each cell using Darcy's law and we assume for simplicity that sea ice is a saturated porous medium. In the vertical direction the Darcy velocity, $v$, reduces to

$$
v=-\pi_{v} \frac{g \rho_{m}}{\mu} \frac{y}{H}
$$

where $\pi_{v}$ is the vertical ice permeability, $g$ is gravitational acceleration, $\mu$ is dynamic viscosity, which, for water, is $10^{-3} \mathrm{~kg} \mathrm{~m}^{-1} \mathrm{~s}^{-1}, \rho_{m}$ is the density of meltwater, which is initially formed from melted snow and is taken to be $1000 \mathrm{kgm}^{-3}, y$ is the height of the melt pond surface above sea level, and $H$ is ice thickness. In the horizontal direction the Darcy velocity, $\mathbf{u}$, is given by

$$
\mathbf{u}=-\pi_{h} \frac{g \rho_{m}}{\mu} \nabla \psi
$$

where $\pi_{h}$ is the ice permeability in the horizontal direction, and $\psi$ is the fluid surface height.

[23] The structure of sea ice is such that the upper surface and several centimeters below the sea ice surface is often a highly porous, crusty layer of sea ice [Eicken et al., 2002]. We assume that most horizontal water transport is limited by flow through this porous crust. The solid fraction in the sea ice crust is lower than that in the ice below and therefore the permeability will be greater here than at any other depth in the sea ice. The permeability at the base of the ice in the summer melt season is small enough to make horizontal water flux greater than vertical water flux for the same pressure gradient, and therefore is the dominant way in which water is transported. In our model horizontal water 
flux is calculated before vertical water flux in a given time step and vertical water flux is calculated if there is any water remaining in the cell.

[24] Permeability studies by Eicken et al. [2002] and Freitag and Eicken [2003] noted that ice permeability varied by several orders of magnitude between the early and late melt season and by several orders of magnitude due to ice type. We have adapted the semiempirical parameterization for vertical permeability introduced by Golden et al. [2007]. This states that the vertical permeability $\pi_{v}$ is determined by the solid volume fraction $\phi$ of ice

$$
\pi_{v}=3 \times(1-\phi)^{3} \times 10^{-10} \mathrm{~m}^{2} .
$$

[25] In the model described here vertical flow is limited by the lowest permeability in a vertical column. During the melt season this occurs at the base of the sea ice, where the solid fraction is considered to be constant since the temperature is fixed at the freezing temperature of sea water. In this case the vertical permeability does not vary with time and we take its value to be $\pi_{v}=2.4 \times 10^{-12} \mathrm{~m}^{2}$. This permeability is at the low end of the scale of observational results, however even with this low permeability our model shows that ponds can drain to sea level in a matter of hours. There is no corresponding model for horizontal permeability, but since permeability in the horizontal direction at any depth within the sea ice is expected to be lower than the permeability in the vertical direction at the same depth, due to the columnar structure of sea ice, we assume that horizontal permeability will always be 2 orders of magnitude smaller than vertical permeability, following Feltham et al. [2006]. Horizontal ice permeability is determined by

$$
\pi_{h}=3 \times(1-\phi)^{3} \times 10^{-12} \mathrm{~m}^{2},
$$

where $\phi$ is the solid fraction at the upper ice surface.

[26] To take into account the effect of an impermeable layer of refrozen snow at the start of the melt season [Eicken et al., 2004], vertical permeability is taken to be zero until snow in that cell has melted away entirely. Snow is assumed to have a horizontal permeability of $3 \times 10^{-9} \mathrm{~m}^{2}$.

\subsection{Heat Transport Model}

[27] The vertical heat transport model is the same as the melt-pond-sea-ice model described by Taylor and Feltham [2004]. This model is quite sophisticated and space is too limited to repeat all the model details; the reader is urged to consult [Taylor and Feltham, 2004]. Here, we provide an outline of the model only. The model represents the following components: snow, sea ice, melt pond, and ice lid (the ice layer that forms on top of the melt pond during the freezeup process). A simple snow model was utilized, following Maykut and Untersteiner [1971]. To conserve mass and energy as the snow melts and forms a melt pond, a nonlinear relationship between density and volume was imposed. The thermodynamic model of the sea ice component (including the ice lid) was described using the equations describing a mushy layer [Feltham et al., 2006], i.e., the sea ice is assumed to consist of a solid matrix of pure ice surrounded by brine (with no air pockets). In the model, heat transport within the melt pond quickly becomes turbulent and the pond is therefore treated as well mixed, with melt pond salinity assumed to remain constant and the four-thirds rule used for turbulent heat fluxes to the atmosphere and pond base. The sea ice-pond and sea ice-ocean interfaces are treated as free surfaces, with their evolution determined by local heat balance (Stefan) equations.

[28] A two-stream radiation model is used for the sea ice and melt pond, based on the earlier work of Perovich [1990], because it enables albedo to be obtained from the inherent optical properties of sea ice, i.e., the optical absorption and scattering coefficients. The scattering properties of the ice beneath a melt pond was parameterized to account for summertime variation. The shortwave albedo (spectral variation within this band was ignored) is defined by

$$
\alpha=R_{0}+\frac{\left(1-R_{0}\right) F_{\uparrow 0}\left(z_{0}=0\right)}{F_{S W}},
$$

where $R_{0}=0.05$ is the Fresnel reflection coefficient [Perovich, 1990], $F_{\uparrow 0}\left(z_{0}=0\right)$ is upwelling irradiance at the ice or pond surface calculated from the radiative model, and $F_{S W}$ is incident shortwave radiation. The albedo depends (through the upwelling irradiance) on the presence and saturation of snow, the presence and depth of meltwater, the presence and depth of an ice lid on top of the melt pond, the depth of the sea ice beneath the melt pond, and the scattering and absorption coefficients of these media.

[29] The melt rate beneath melt ponds is related to pond depth through the dependence of radiative heating on pond depth, and to ice thickness through the dependence of the conductive flux through the sea ice to the ocean on ice thickness. The albedo of ponded ice decreases with increasing pond depth, although the dependence is rather weak with no sensible decrease in albedo for ponds deeper than about a meter.

[30] The thermodynamic and radiative model input forcing data are: incoming short-wave radiation; incoming longwave radiation; air temperature at $10 \mathrm{~m}$ (used in determining the sensible heat flux); specific humidity at $10 \mathrm{~m}$ (used in determining the latent heat flux); air pressure (used in determining the latent heat flux); wind speed at $10 \mathrm{~m}$ (used in determining the latent and sensible heat fluxes); and ocean heat flux. All forcing data is identical to that described by Taylor and Feltham [2004], is diurnally averaged, and is based on measurements made during the Surface and HEat Budget of the Arctic (SHEBA) field study [Perovich et al., 1999]. The Maykut and Untersteiner [1971] snow cover was used.

\subsection{Topography Model and Standard First-Year and Multiyear Sea Ice Topographies}

[31] Due to the limited availability of sea ice topography and snow topography data, and in particular combined data, some assumptions have been made in modeling the snow and ice topographies. In particular, we assume that both snow and ice topographies are isotropic and that there is no correlation between snow depth and ice thickness.

[32] We generated sea ice topography and snow thickness using the statistical software package "R project" using the random field method, a method used in geostatistics to generate or reconstruct spatially defined data. To create a surface topography using the random field method some 
Table 1. Mean and Variance of Ice Thickness and Snow Thickness for First-Year and Multiyear Ice ${ }^{\mathrm{a}}$

\begin{tabular}{lcccc}
\hline Ice Type & $\begin{array}{c}\text { Ice Mean } \\
(\mathrm{m})\end{array}$ & $\begin{array}{c}\text { Ice Standard } \\
\text { Deviation }(\mathrm{m})\end{array}$ & $\begin{array}{c}\text { Snow Mean } \\
(\mathrm{m})\end{array}$ & $\begin{array}{c}\text { Snow Standard } \\
\text { Deviation }(\mathrm{m})\end{array}$ \\
\hline First-year & 1.70 & 0.20 & 0.31 & 0.15 \\
Multiyear & 2.50 & 1.10 & 0.30 & 0.25 \\
\hline
\end{tabular}

${ }^{a}$ These are the values used to create initial ice and snow surface topographies for the standard cases.

knowledge of the surface is required. The mean and variance of snow or ice depth is needed, which can be recovered from field data, and a covariance model is used to determine the correlation between snow or ice thicknesses at separate locations as the distance between locations increases. Following Sturm et al. [2002] the covariance model that best describes the sea ice and snow thickness distribution is the spherical covariance model

$$
C(\lambda)=\frac{2}{\pi}\left[\arccos \left(\frac{\lambda}{a}\right)-\frac{\lambda}{a} \sqrt{\left(1-\frac{\lambda^{2}}{a^{2}}\right)}\right], \quad \lambda<a
$$

and

$$
C(\lambda)=0, \lambda \geq a,
$$

where $\lambda$ is the distance between locations, and $a$ is the range, which is the distance beyond which there is no correlation. This covariance model describes a surface which is reasonably smooth over the range scale.

[33] To create an ice topography two ice topographies were initially generated, one representing ice draft below a putative sea level and one representing freeboard ice height above a putative sea level. The draft and freeboard topographies were then combined to produce the total ice topography. On top of the ice topography, a snow thickness field was added. The position of sea level was then recalculated from a reference height using a hydrostatic balance over the whole domain, taking into account the additional mass of snow.

[34] We now describe the construction of the standard first-year and multiyear ice topographies used in this study. As part of the SHEBA field study, Sturm et al. [2002] found that the Arctic snow cover distribution could be modeled by the spherical covariance model with a range of $20 \mathrm{~m}$. Mean snow depth was $33.7 \mathrm{~cm}$ with a standard deviation of 19.3 $\mathrm{cm}$. Snow depths ranged from 0 to $1.50 \mathrm{~m}$. During the SHEBA field study, measurements of ice thickness were taken at intervals of $5 \mathrm{~m}$ along a series of straight lines of between $200 \mathrm{~m}$ and $500 \mathrm{~m}$ in length across the sea ice surface. From these ice thickness measurements the mean and standard deviation of each ice type were evaluated. The sea ice range was taken to be $10 \mathrm{~m}$, following Sturm et al. [2002]. Table 1 shows the mean and standard deviation in ice thickness and snow depth that were used to initialize the standard model runs. The mean ice depth used to generate the initial ice draft and freeboard topography were $90 \%$ and $10 \%$, respectively, of the values shown in Table 1 . The freeboard depths could be negative indicating a surface below sea level.

[35] A mean ice thickness of $1.70 \mathrm{~m}$ was selected for the first-year ice standard case, this is a mean ice thickness of first-year ice with a thin snow cover as observed by
Perovich et al. [2002b]. The standard deviation in ice thickness is $0.20 \mathrm{~m}$ which was determined from ice thickness measurements in the SHEBA data set. Initial mean snow depth is $0.3 \mathrm{~m}$, with a standard deviation of $0.15 \mathrm{~m}$. Requiring that the snow cover thickness on each cell was nonnegative resulted in a slight increase of mean snow depth to $0.31 \mathrm{~m}$. Although this standard case first-year ice is relatively thick, choosing a significantly thinner ice thickness would result in the ice melting away completely. The firstyear ice thickness we have selected results in about $50 \%$ of the ice melting completely, with the remaining ice surviving to form multiyear ice. This allows us to reproduce the full melt pond cycle, which is the purpose of this study.

[36] The mean ice thickness for the multiyear ice standard case was selected to be $2.5 \mathrm{~m}$, which is the mean multiyear ice thickness observed in the SHEBA field experiment [Perovich et al., 1999]. The standard deviation in ice thickness is $1.1 \mathrm{~m}$, which is greater than the standard deviation of $0.53 \mathrm{~m}$ calculated from the SHEBA field data but is in the range of overall observations (Lüthje et al. [2006] uses a standard deviation of $1.5 \mathrm{~m}$ ). Due to the increased variability in ice thickness compared to the firstyear ice case, $6 \%$ of the cells have a zero initial ice thickness, which is a limitation of the method of generating topography but since it does not affect the evolution of the ice covered fraction (and is within the range of observations) it is considered acceptable here. Initial mean snow depth is $0.3 \mathrm{~m}$, the same as the mean snow depth in the first-year ice case, but with a greater standard deviation of $0.25 \mathrm{~m}$ corresponding to snow observed on "hummocky" multiyear ice by Sturm et al. [2002].

[37] Figures 2 and 3 show the initial ice and snow topographies that were used for the standard runs and how they appeared once sea level with respect to the grid had been established. Note that points of greatest ice thickness do not necessarily have the greatest ice surface height above sea level. These Figures 2 and 3 show some regions with a significantly negative freeboard. This is most likely unrealistic and indicates a deficiency in using a simulated rather than measured topography. Since these regions occupy only a small fraction of the total surface area, we deem their presence to be an acceptable compromise. In the future, one would hope for accurate measurements of topography to initialize the model. Recent measurements using light detection and ranging (C. Polashenski and D. Perovich, personal communication, 2010) offer some hope for this.

\section{First-Year and Multiyear Sea Ice Standard Cases: Results and Discussion}

\subsection{Standard Case Simulation Results}

[38] The model runs start on 20 May (day 140) and run for 90 days with a time step of $1 \mathrm{~h}$. Day 140 is several days before the snow begins to melt. The standard runs were initialized with ice and snow surfaces that represent firstyear ice and multiyear ice, as described in section 2.3.

\subsubsection{First-Year Ice Standard Case}

[39] Figure 4 shows the development of ponds across the surface of first-year ice with time. Ponds remain at the location of initial formation, widening and deepening. The final plot of pond coverage on day 210 shows that the deepest ponds have melted through to the ocean and pond 

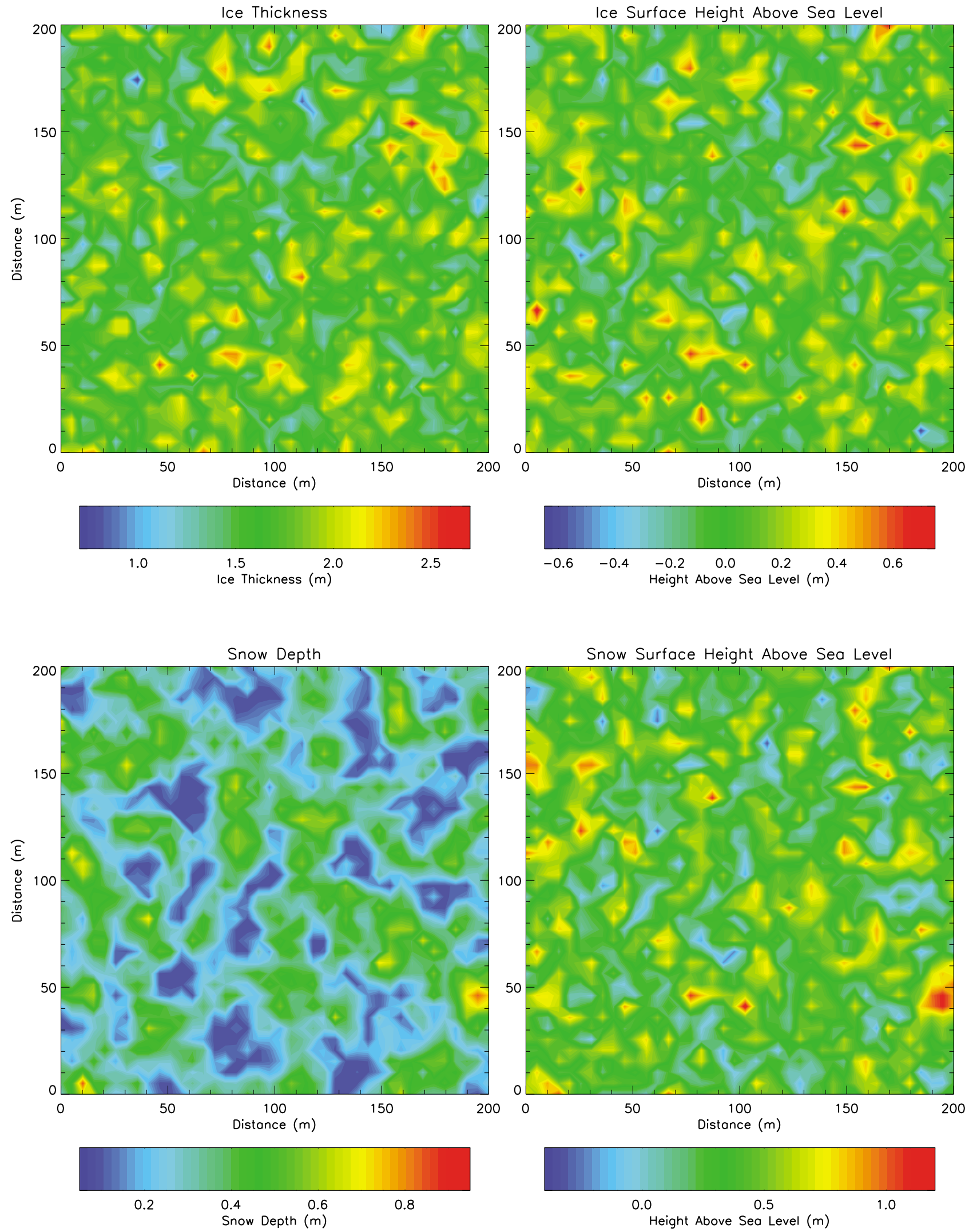

Figure 2. (left) Contour plots of the initial first-year ice mean ice thickness and snow depth in each cell. (right) The height of the ice surface above sea level and the height of the snow surface above sea level. Surface heights above sea level can be negative. 

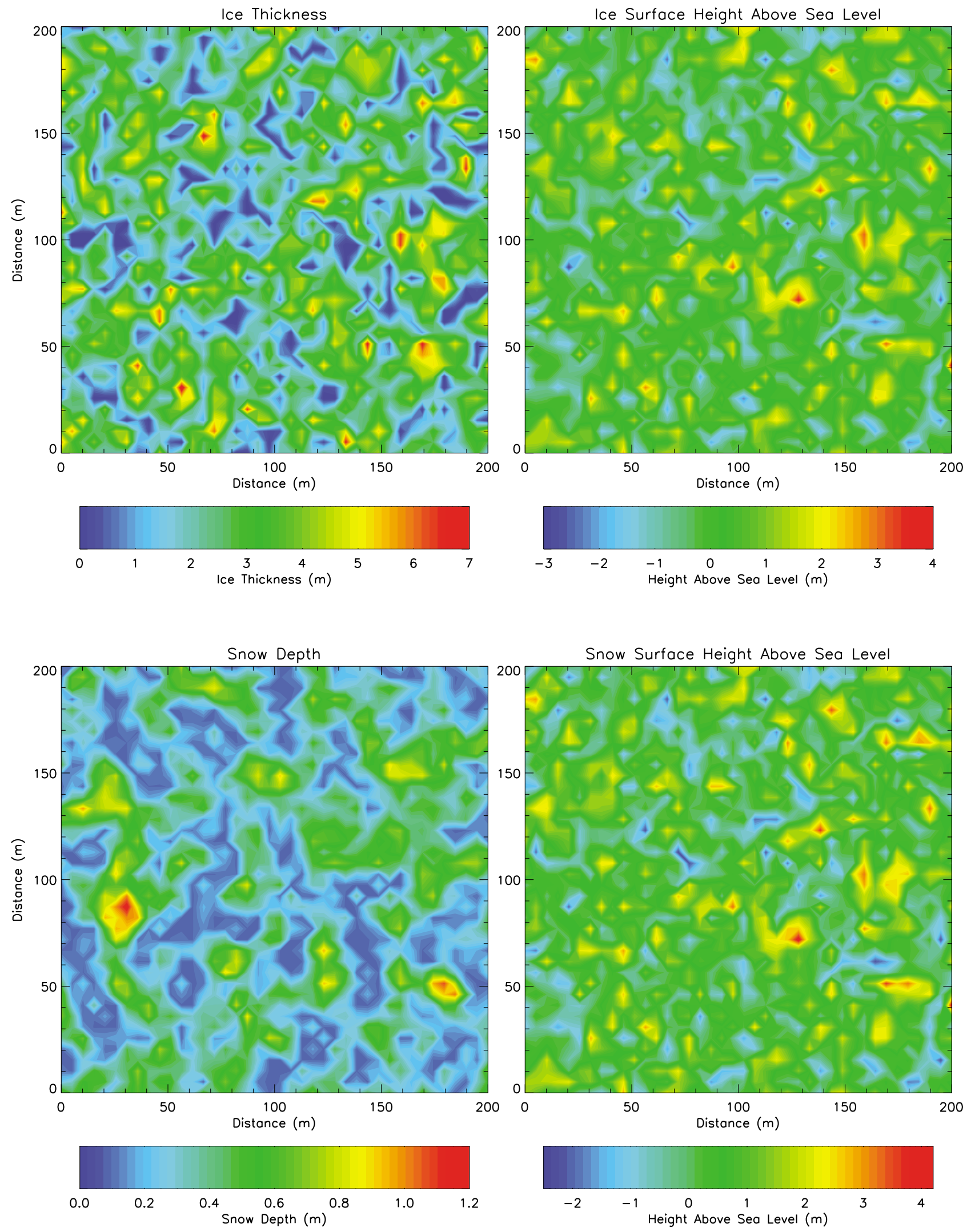

Figure 3. (left) Contour plots of the initial multiyear ice mean ice thickness and snow depth in each cell. (right) The height of the ice surface above sea level and the height of the snow surface above sea level. Surface heights above sea level can be negative. 

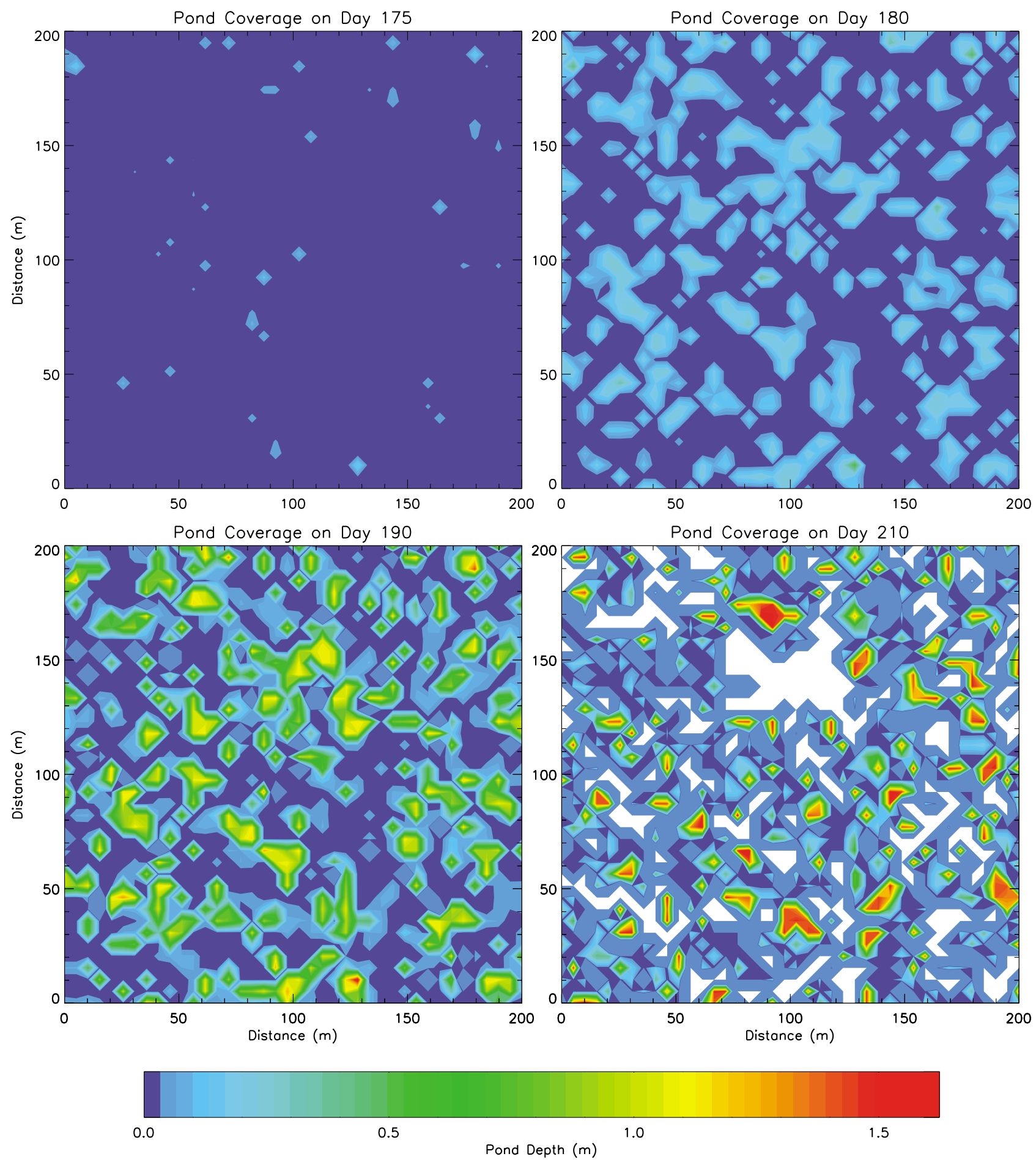

Figure 4. Contour plots showing simulated pond depth on first-year ice during the melt season. Pond depth on the day that ponds initially form (on day 175) and pond coverage before freezeup (on day 210) are shown. Dark blue represents bare ice, and pond depth scale is illustrated in the color bar with red for the deepest ponds. White regions are areas where sea ice has melted through entirely. 

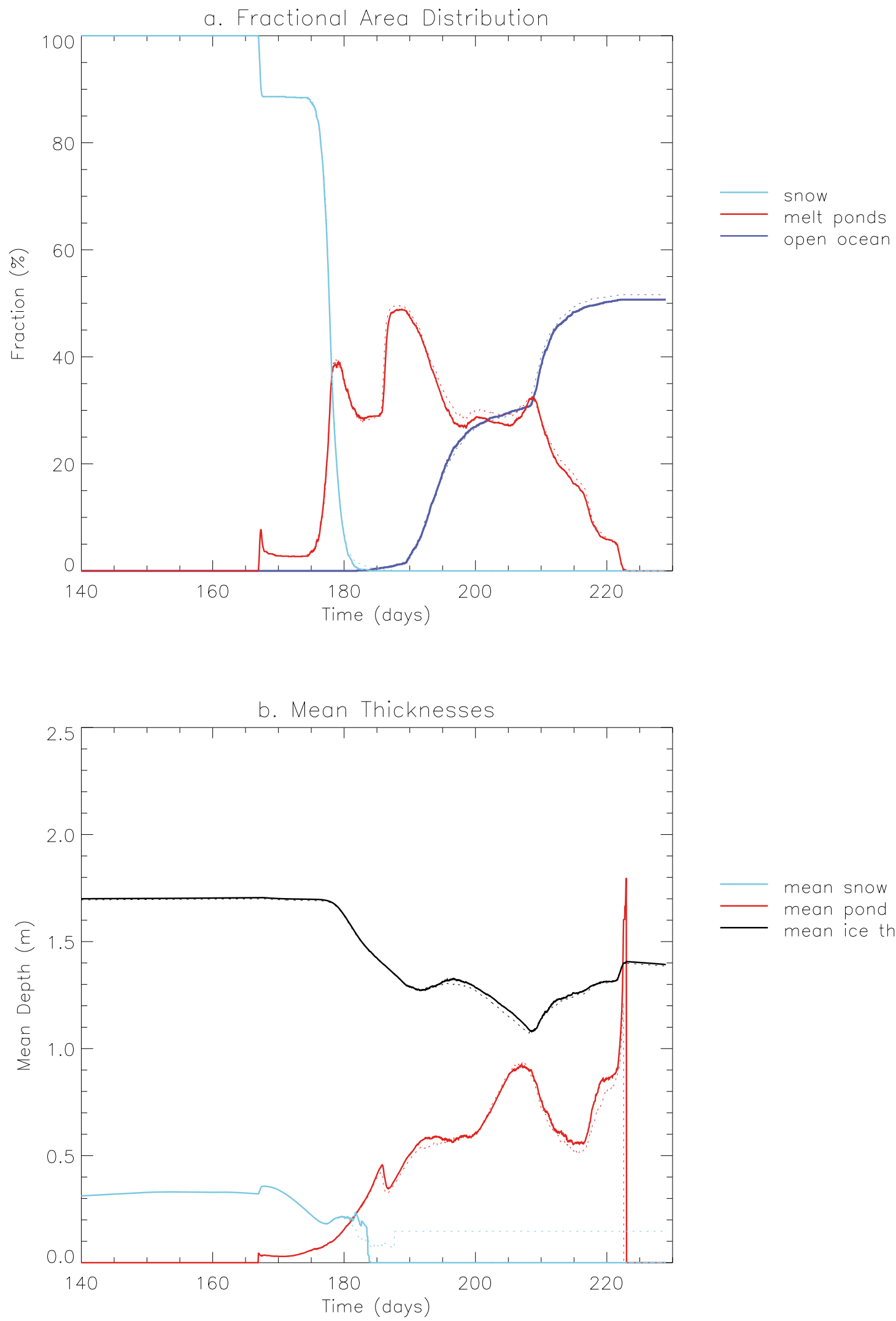

mean snow thickness

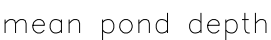

mean ice thickness

Figure 5 


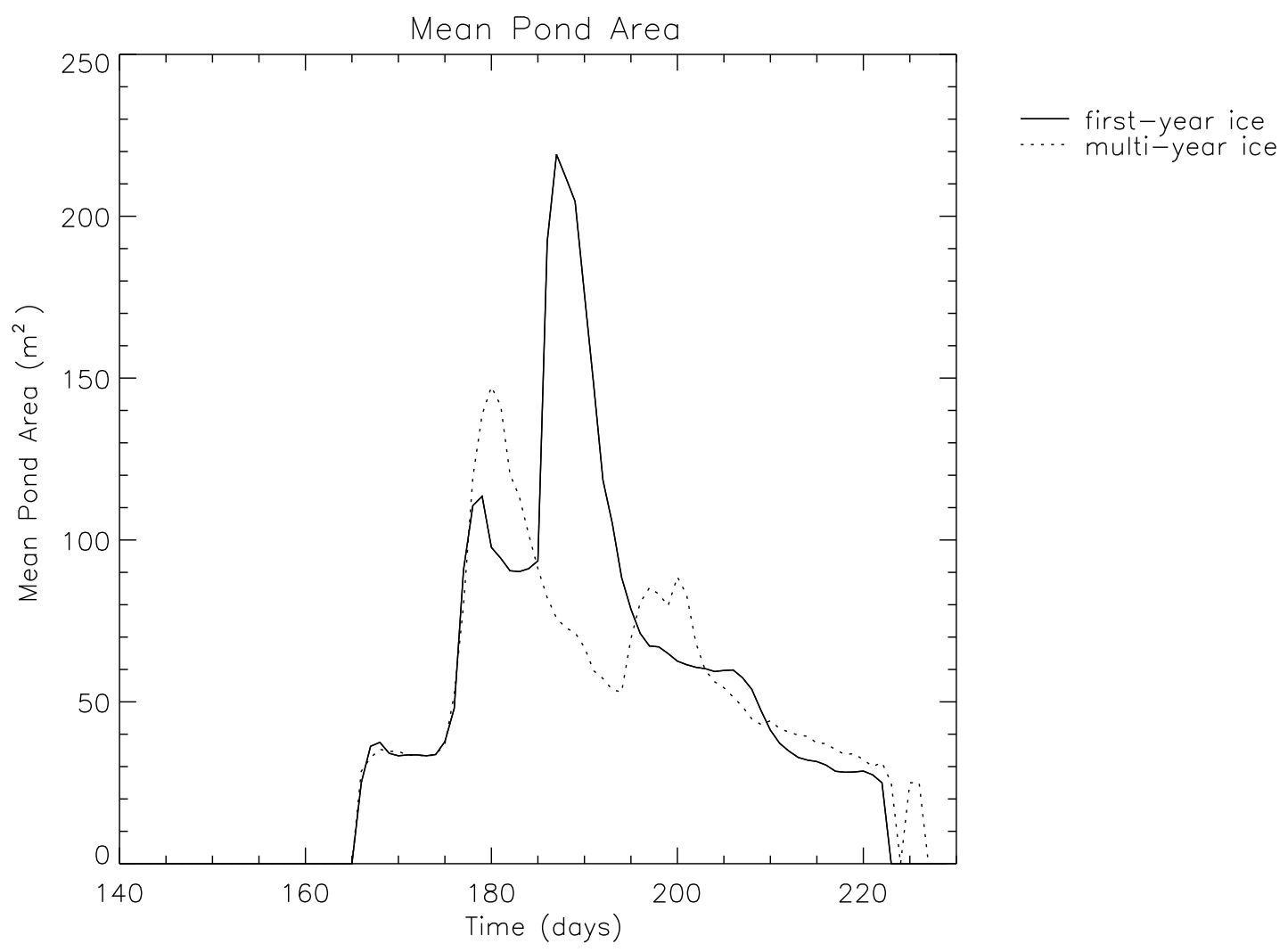

Figure 6. Mean individual pond area for first-year ice (solid line) and multiyear ice (dashed line).

surface area is now shrinking again, although ponds are at their deepest.

[40] Evolution of the fraction of the surface covered in ocean, pond or snow and mean ice, snow and pond depth are illustrated in Figure 5. We found that starting topographies with the same initial mean depth and standard deviation yielded very similar results (see dashed lines in Figure 5). The first ponds form on day 167 as the thinnest snow melts away, $7 \%$ of the surface is covered in ponds at this time. The fraction of the surface covered in snow remains constant for several days until thicker snow melts through entirely, exposing the ice beneath. The maxima in pond area fraction reached on day 179 coincides with all the remaining snow being removed. By day 183 the thinnest ice melts away, a cell with no ice is considered to be open ocean and any water transported into these cells is considered to be lost to the ocean. The increase in drainage areas due to cells melting through occurs at the same time as an increase in melt rate and thus pond coverage actually increases by $10 \%$ between days 185 and 187 , when it reaches it maximum of $49 \%$. Mean pond area (Figure 6) reaches its maximum at the same time, however mean pond depth continues to increase due to enhanced melting beneath ponds and water being transported across the surface to the cells with the smallest ice surface height. Mean pond depth reaches a local maximum on day 207 of $0.9 \mathrm{~m}$ which is just prior to pond coverage decreasing due to pond surfaces freezing over. As soon as the pond surface in a given cell has frozen over the cell is categorized as an ice cell even if the full depth of the pond has not frozen. Thinner ponds freeze over before deeper ponds, hence the sharp increase in mean pond depth from day 215. The percentage decrease in mass over the modeled melt season is $62.2 \%$ and the total ice ablation is $1.01 \mathrm{~m}$.

[41] The area averaged albedo of the entire domain (this includes open ocean cells) decreases steadily with time once snow had begun melting. The minimum value for the albedo, of 0.32, (shown in Figure 7) is reached on day 216,

Figure 5. (a) Variation in the fractional distribution of surface area with time for the standard first-year ice case, where mean ice thickness is $1.70 \mathrm{~m}$, standard deviation in ice thickness is $0.20 \mathrm{~m}$, mean snow thickness is $0.31 \mathrm{~m}$, and standard deviation in snow thickness is $0.15 \mathrm{~m}$. Fraction of the surface with a snow cover is light blue, fraction of the surface covered with melt ponds is red, and fraction of the surface with no ice cover (open ocean) is dark blue. The dashed lines represent corresponding fractions for the alternative first-year ice case. (b) Change in mean snow depth (light blue), mean pond depth (red), and mean ice thickness (black) with time for the standard first-year ice case, with dashed lines representing the corresponding values for the alternative first-year ice case. 


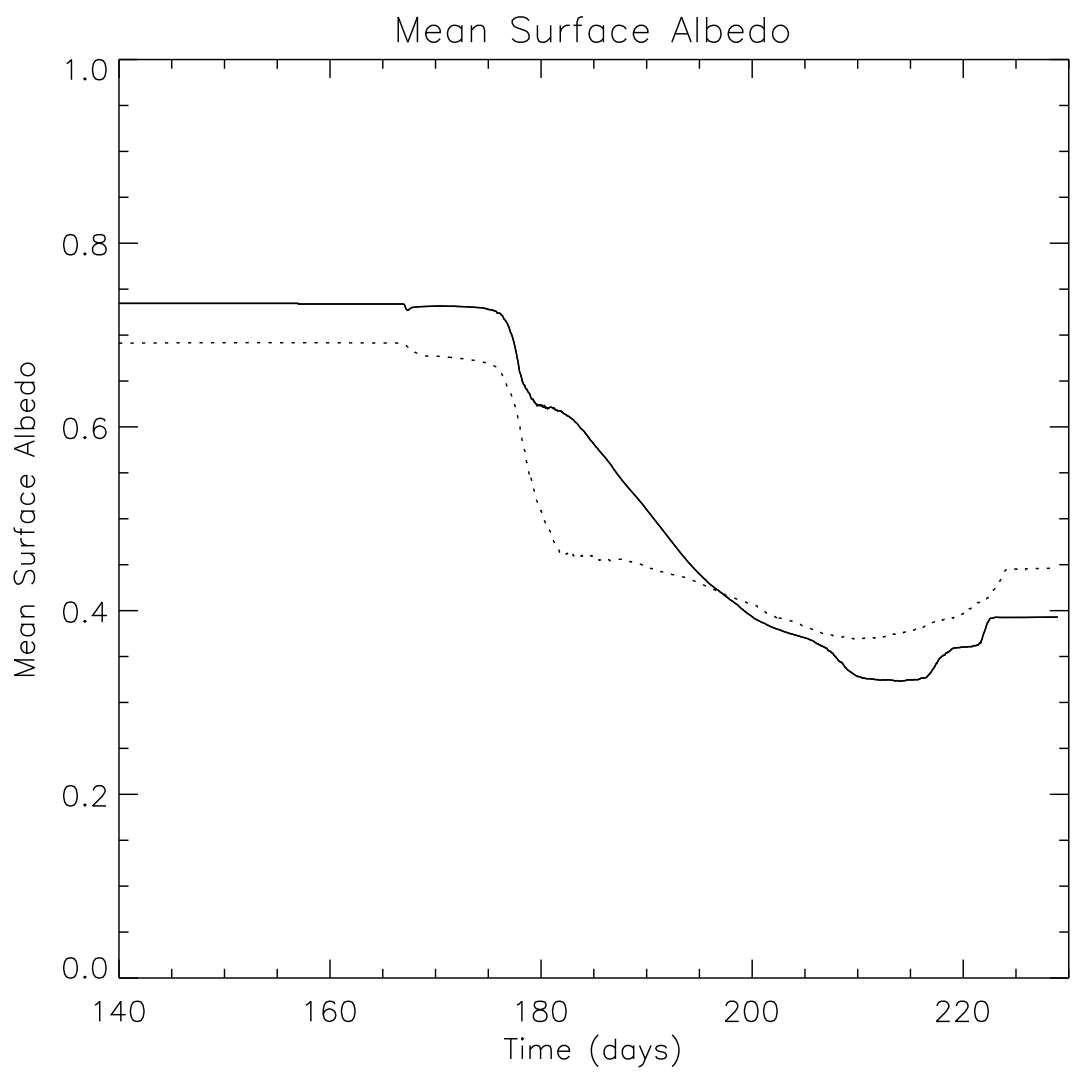

- first-year ice
multi-year ice

Figure 7. Change of area-averaged surface albedo with time for first-year ice (solid line) and multiyear ice (dashed line).

after this the albedo increases again as ponds freeze over. By the end of the melt season the albedo has increased to 0.39 , which is well below the wintertime value, this is due to $50 \%$ of the surface now being open ocean.

\subsubsection{Multiyear Ice Standard Case}

[42] Figure 8 shows the development of ponds across the surface of multiyear ice with time. Evolution of the fraction of the surface covered in ocean, pond or snow and mean ice, snow and pond depth are illustrated in Figure 9. Initial ponds form on day 166 , which is a day earlier than initial pond formation in the first-year ice standard case due to the increased variability in snow thickness meaning that some cells may have thinner snow than in the first-year ice case. The majority of the snow cover is removed by day 183 two later than in the first-year ice case, however $9 \%$ of cells still have a non zero snow cover at this time and snow cover is not entirely removed from these cells until day 205, 26 days later. Similar to the first-year ice standard case, a large pond fraction is reached which coincides with the majority of the snow melting away. In the first-year ice case this is only a local maxima but in the multiyear ice case the maximum pond fraction, $47.1 \%$, is reached on day 181 . Due to the increased roughness of the ice surface compared to the firstyear ice case meltwater in the multiyear ice case cannot travel far horizontally across the surface due to the prevalence of deep depressions in the ice cells, shown in Figure 8. Ponds persist in the regions where they first accumulate, these are the lowest regions of the surface, where the ice surface is below sea level. Pond surface height at these lo- cations start with a surface height below sea level and as pond depth increases pond surface height eventually reaches sea level. These ponds are able to drain as thin ice melts through to the ocean and the average thickness of the floe, and freeboard, increases creating a positive hydraulic head. The increase in pond fraction between days 195 and 197 is due to an increase in melt rate and large ice surface area remaining.

[43] The decrease in mean ice thickness is less rapid than in the first-year ice case because the temperature gradient in the thicker sea ice is smaller than the temperature gradient in thinner ice. The increase in mean ice thickness at the end of the season is due to ponded cells freezing over and being reclassified as ice cells. The fractional decrease in mass over the season is less than the first-year ice case at $54 \%$, due to the greater initial ice volume. However ice ablation of 1.32 $\mathrm{m}$ in the multiyear ice case exceeds ice ablation in the firstyear ice case. This is because the thicker ice in the multiyear ice case provides more ice to melt.

[44] Mean pond depth is greater in the multiyear ice case than the first-year ice case, mean pond depth exceeds $1 \mathrm{~m}$ by day 191 and continues to increase, whereas in the firstyear ice case mean pond depth does not exceed $1 \mathrm{~m}$ for most of the season, although there are ponds deeper than this as is apparent in the mean pond depth plot at the end of the season.

[45] The mean pond area maximum (Figure 6) in both the first-year ice and multiyear ice cases occurs when the majority of the snow has melted, flooding the ice surface. 

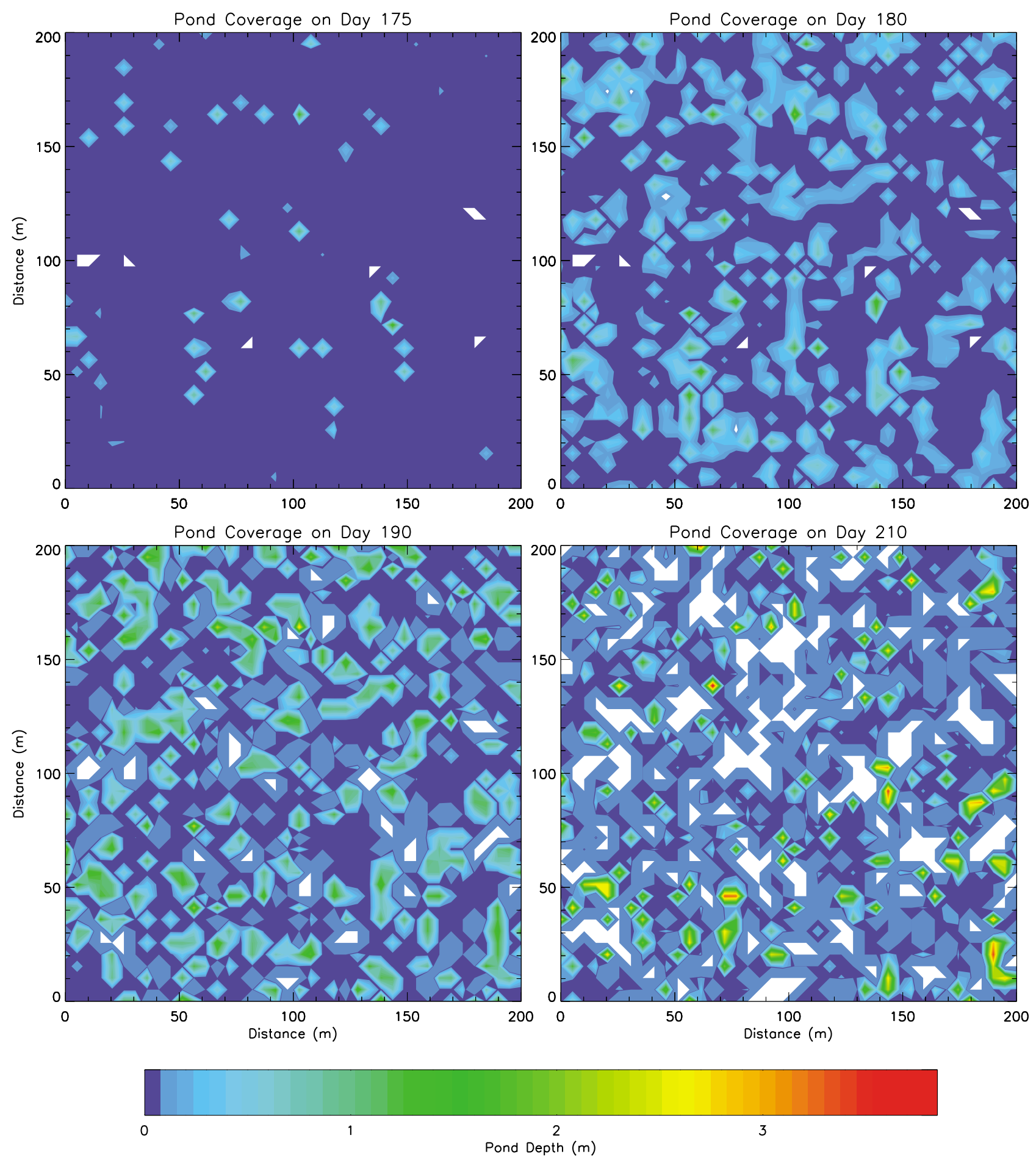

Figure 8. Contour plots showing simulated pond depth on multiyear ice during the melt season. Note the color scale is different from that in Figure 4. Pond depth on the day that ponds initially form (on day 175) and pond coverage before freezeup (on day 210) are shown. Dark blue represents bare ice, and pond depth scale is illustrated in the color bar with red for the deepest ponds. White regions are areas where sea ice has melted through entirely. 
a. Fractional Area Distribution

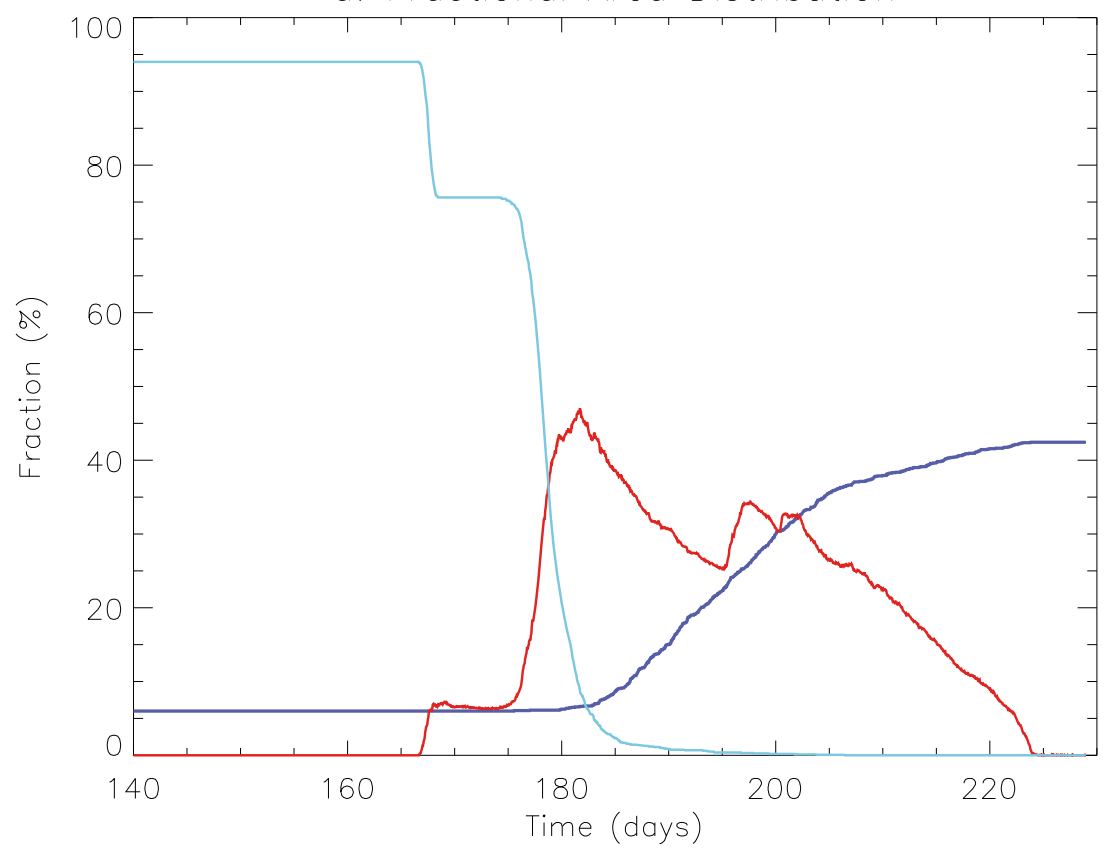

b.Mean Thicknesses

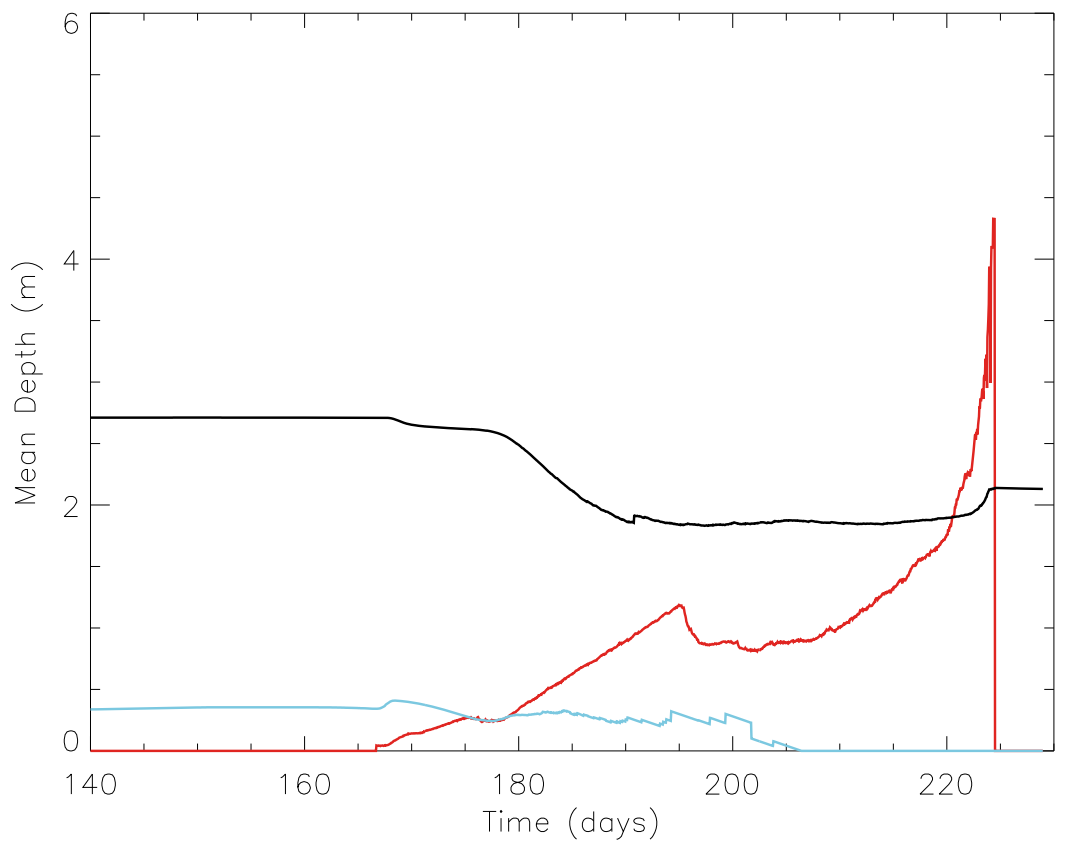

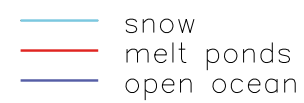

melt ponds
open ocean

Figure 9. (a) Variation in the fractional distribution of surface area with time for the standard multiyear ice case, where mean ice thickness is $2.50 \mathrm{~m}$, standard deviation in ice thickness is $1.10 \mathrm{~m}$, mean snow thickness is $0.30 \mathrm{~m}$, and standard deviation in snow thickness is $0.25 \mathrm{~m}$. Fraction of the surface with a snow cover is light blue, fraction of the surface covered with melt ponds is red, and fraction of the surface with no ice cover (open ocean) is dark blue. (b) Change in mean snow depth (light blue), mean pond depth (red), and mean ice thickness (black) with time for the standard multiyear ice case. 
However the differences in ice topography generate much larger mean pond area in the first-year ice case than in the standard case. Maximum mean pond area in the first-year ice case is $219 \mathrm{~m}^{2}$ and in the multiyear ice case maximum mean pond area is 1.5 times smaller at $147 \mathrm{~m}^{2}$.

[46] In the multiyear ice case the mean surface albedo (Figure 7) decreases rapidly as snow melt produces ponds and continues to decrease more slowly until the ponds freeze over. This is unlike the first-year ice standard case where the greatest rate at which the albedo decreases corresponds to increasing pond fraction later in the season. The lowest albedo in both cases occurs just before freezeup and in the multiyear ice case is 0.37 compared to 0.32 in the first-year ice case.

\subsection{Discussion of Standard Cases}

\subsubsection{Comparison of Standard Case Simulations With Observations}

[47] There is typically substantial variation between observations of melt ponds since observations are made at different points in the melt season and at different locations. However initial pond formation on both first-year ice and multiyear ice in our model occurred within 3 days of that observed by El Naggar et al. [1998] and widespread coverage in the model by day 174 compares well with the same event observed by Perovich et al. [2002a]. The model is forced with atmospheric data collected during the SHEBA field study so the similarity in the pattern of pond coverage at the start of the season is evidence that the model is performing well. The maximum pond fraction observed by Perovich et al. [2002a] was around day 174,early in the season, after this pond fraction decreased, which is a pattern seen in both the first-year ice and multiyear ice modeled standard cases where there is a peak in pond coverage after snow cover is removed. The initial increase in ocean fraction in both the first-year ice and multiyear ice standard cases is close to the values observed in aerial photographs by Tschudi et al. [2001]. On day 190, Tschudi et al. [2001] observed open ocean of approximately $5 \%$, however the ocean fraction increases far more rapidly in both the firstyear ice and multiyear ice standard cases than in the observations made by Tschudi et al. [2001] toward the end of the season. This is most likely due to convergence of the ice pack, which is not modeled here.

[48] Whilst the general evolution of pond fraction compares well to observations there is much variability in observed pond fraction even in nearby locations [Yackel et $a l ., 2000]$. There is most variability in pond fractions on first-year ice. In the first-year ice standard case the maximum fraction of the ice surface covered with ponds is $49 \%$ and mean pond fraction was $32 \%$ over the period when ponds were present. El Naggar et al. [1998] found the mean pond fraction on first-year ice to be between $20 \%$ and $48 \%$, Fetterer and Untersteiner [1998] observe pond fraction of smooth ice to be between $30 \%$ and $50 \%$ and Eicken et al. [2004] observe pond fraction to vary between $10 \%$ and $60 \%$ on first-year ice. Our values fall into this range.

[49] Eicken et al. [2004] observed a maximum pond fraction on level multiyear ice to be between $29 \%$ and $46 \%$ and the multiyear ice model results presented here, which were intended to model level multiyear ice, compare well with these observations.
[50] Fetterer and Untersteiner [1998] and Yackel et al. [2000] found that ponds on first-year ice had a larger surface area than ponds on multiyear ice and that there were more ponds on multiyear ice than on first-year ice because they are constrained by the ice surface topography with ponds often forming in depressions made by previously drained ponds. This observation was reproduced in the standard case runs, maximum mean pond area was 1.5 times greater on first-year ice than on multiyear ice. In both the first-year ice and multiyear ice standard cases ponds persist where they form initially, maximum mean pond area in the first-year ice case is $219 \mathrm{~m}^{2}$ and maximum mean pond area in the multiyear ice case is $147 \mathrm{~m}^{2}$. Tucker et al. [1999] calculated a mean pond area of $63 \mathrm{~m}^{2}$ on sea ice in the Eurasian Arctic, this is less than half the area of the maximum mean pond area in the multiyear case. However minimum pond area was $2 \mathrm{~m}^{2}$ in the Tucker et al. [1999] observations and maximum pond area was $8000 \mathrm{~m}^{2}$, so there is clearly much variability and pond area is dependent on individual floe topography. Eicken et al. [2004] noticed mean pond area decreasing in the second half of the season, this is similar to both the first-year ice and multiyear ice standard cases.

[51] The mean albedo of the ice surface over the melt season in the first-year ice case is 0.64 and over the entire domain (which includes open ocean) is 0.56 . In the multiyear ice case the mean albedo over the ice surface is 0.64 and over the entire domain is 0.53. Hanesiak et al. [2001] and Yackel et al. [2000] calculated the total surface albedo over first-year ice across photographed transects of an ice floe and found the average albedo to be 0.55 , which is much less than the modeled first-year ice albedo of 0.64. Eicken et al. [2004] compared mean pond fraction with total albedo and found that on a region of first-year ice where the mean pond fraction was $26 \%$ the mean albedo was 0.45 , which can be compared with a mean area of the total grid covered with ponds in the first-year ice standard case of $25.4 \%$ and mean albedo of 0.56 . In all comparisons with observations the modeled mean albedo is greater than the observed mean albedo. This indicates that while the heat transfer model is generating reasonable melting rates (which is to be expected since the model was calibrated using SHEBA data), it is generating them for the wrong reason. One of the chief areas of uncertainty in the model is in the value and evolution of the optical scattering coefficient of ice beneath melt ponds [see Taylor and Feltham, 2004]. Careful measurements of the transmission and absorption of solar radiation of ponded ice, similar in kind to those performed by Light et al. [2008] but for ponded ice, would help improve the model.

\subsubsection{Comparison of Standard Case Simulations} With Previous Simulations of Lüthje et al. [2006]

[52] The model described in this paper can be considered to be an extension of the Lüthje et al. [2006] model, where we have introduced explicit hydraulic and thermodynamic and radiative models, which allow the calculation of vertical drainage rates from the evolving freeboard and melt rates from a thermodynamic and radiative model using observed forcing data, rather than these being imposed and tuned. In addition, the model introduced here has an explicit snow cover. We briefly compare the results of the model presented in this paper with that of Lüthje et al. [2006] to 
Table 2. Summary of Important Results From the Standard First-Year Ice Case and Sensitivity Studies ${ }^{\mathrm{a}}$

\begin{tabular}{|c|c|c|c|c|c|c|c|}
\hline $\begin{array}{l}\text { First-Year Ice } \\
\text { Model Run }\end{array}$ & $\begin{array}{c}\text { Mean Ice } \\
\text { Thickness }^{\mathrm{b}}(\mathrm{m})\end{array}$ & $\begin{array}{c}\text { Mean Snow } \\
\text { Thickness }^{\mathrm{b}}(\mathrm{m})\end{array}$ & $\begin{array}{l}\text { Ice Ablation } \\
(\mathrm{m})\end{array}$ & $\begin{array}{c}\text { Ice and Snow } \\
\text { Ablation (m) }\end{array}$ & $\begin{array}{l}\text { Maximum Pond } \\
\text { Fraction }(\%)\end{array}$ & $\begin{array}{c}\text { Minimum Area } \\
\text { Averaged Albedo }\end{array}$ & $\begin{array}{c}\text { Change in Ocean } \\
\text { Fraction }\end{array}$ \\
\hline Standard case & $1.70(0.20)$ & $0.31(0.15)$ & 1.01 & 1.33 & 49 & 0.32 & 0.51 \\
\hline Thick snow & $1.70(0.20)$ & $0.50(0.15)$ & 1.62 & 2.15 & 94 & 0.09 & 0.95 \\
\hline Thin snow & $1.70(0.20)$ & $0.24(0.15)$ & 0.87 & 1.10 & 38 & 0.37 & 0.40 \\
\hline Rough snow & $1.70(0.20)$ & $0.34(0.25)$ & 1.07 & 1.45 & 54 & 0.30 & 0.56 \\
\hline Smooth snow & $1.70(0.20)$ & $0.30(0.10)$ & 1.00 & 1.31 & 48 & 0.32 & 0.49 \\
\hline Rough ice & $1.70(0.50)$ & $0.30(0.15)$ & 1.12 & 1.44 & 56 & 0.24 & 0.59 \\
\hline Smooth ice & $1.70(0.02)$ & $0.30(0.15)$ & 0.39 & 0.70 & 50 & 0.46 & 0.08 \\
\hline High permeability & $1.70(0.20)$ & $0.31(0.15)$ & 0.96 & 1.28 & 44 & 0.34 & 0.45 \\
\hline Low permeability & $1.70(0.20)$ & $0.31(0.15)$ & 1.53 & 1.84 & 91 & 0.12 & 0.89 \\
\hline
\end{tabular}

${ }^{a}$ Ablation is expressed as a decrease in mean thickness across the whole domain.

${ }^{\mathrm{b}}$ Standard deviations given in parentheses.

indicate the impact of the more realistic physics. More details are given by Scott [2009].

[53] There are similarities in the pattern of pond coverage between the Lüthje et al. [2006] model and the model presented here: in both models first-year ice had wider, shallower ponds than multiyear ice and ablation was greater on multiyear ice. However, despite the Lüthje et al. [2006] model using initial first-year and multiyear ice topographies of similar roughness to those in this paper and using a melting season of about the same duration, the pond fraction, mean pond area and pond depth were often very different, particularly for first-year ice. The maximum pond fraction of $81 \%$ in the Lüthje et al. [2006] model is almost double the maximum pond fraction of $48 \%$ in the first-year ice case of the model presented here. The inclusion of a sea level calculation and modeling vertical drainage by Darcy's law made a substantial difference to pond fraction, particularly in the first-year ice case.

[54] The total ablation for first-year ice in the Lüthje et al. [2006] model of $0.75 \mathrm{~m}$, was much less than the total ablation of $1.33 \mathrm{~m}$ in the model described here, this is due to the greater mass of water available in our model, due to the separate snow layer and the greater ice mean ice thickness.

[55] The multiyear ice standard cases in the Lüthje et al. [2006] model and the multiyear ice standard case described here had similarities in the initial ice topography. Standard deviation in ice thickness is $1.2 \mathrm{~m}$ in the multiyear ice standard case described here and $1.5 \mathrm{~m}$ in the Lüthje et al. [2006] mean multiyear ice standard case. There is an additional snow layer in our model, which has a mean thickness of $0.3 \mathrm{~m}$ and standard deviation of $0.25 \mathrm{~m}$. Mean ice thickness is greater in the Lüthje et al. [2006] standard case, $3.67 \mathrm{~m}$ compared to $2.5 \mathrm{~m}$ in our model. The maximum pond fraction of $45 \%$ in the Lüthje et al. [2006] model compared closely to $47 \%$ in the multiyear ice case described here. The mean pond fraction over the season is $34 \%$ in the Lüthje et al. [2006] model, which is similar to the $32 \%$ in the multiyear ice standard case described here.

[56] The combined ice and snow ablation in the multiyear ice standard case described here is $1.74 \mathrm{~m}$, in the Lüthje et al. [2006] model the total ablation is $0.91 \mathrm{~m}$, which is too low for multiyear ice total ablation, given that the SHEBA study measured a combined first-year and multiyear ice ablation of $1.26 \mathrm{~m}$ [Perovich et al., 2003]. The low total ablation value is probably due to a combination of the fixed drainage rate and fixed melt rate used in the Lüthje et al. [2006] model, with the large surface areas covered with ponds suggesting that the drainage rate is too low. Total ablation has been improved in our model by calculating heat flux through the ice and accounting for basal melting. Mean pond depth in the Lüthje et al. [2006] multiyear ice case is $0.57 \mathrm{~m}$ compared to $0.85 \mathrm{~m}$ in our multiyear ice case. The topography model used in our study allows ice cells to have a surface below sea level, which enabled deeper initial mean pond depths, which then deepened further due to the enhanced melt rate beneath ponds.

\section{Sensitivity Studies: Results and Discussion}

[57] Below we present sensitivity studies that examine the impact on pond cover and ice and snow ablation of changes in snow topography, ice topography, and vertical perme-

Table 3. Summary of Important Results From the Standard Multiyear Ice Case and Sensitivity Studies ${ }^{\mathrm{a}}$

\begin{tabular}{|c|c|c|c|c|c|c|c|}
\hline $\begin{array}{c}\text { Multiyear Ice } \\
\text { Model Runs }\end{array}$ & $\begin{array}{c}\text { Mean Ice } \\
\text { Thickness }^{\mathrm{b}}(\mathrm{m})\end{array}$ & $\begin{array}{c}\text { Mean Snow } \\
\text { Thickness }^{\mathrm{b}}(\mathrm{m})\end{array}$ & $\begin{array}{c}\text { Ice Ablation } \\
(\mathrm{m})\end{array}$ & $\begin{array}{l}\text { Ice and Snow } \\
\text { Ablation (m) }\end{array}$ & $\begin{array}{l}\text { Maximum Pond } \\
\text { Fraction }(\%)\end{array}$ & $\begin{array}{c}\text { Minimum Area } \\
\text { Averaged Albedo }\end{array}$ & $\begin{array}{c}\text { Change in Ocean } \\
\text { Fraction }\end{array}$ \\
\hline Standard case & $2.50(1.10)$ & $0.30(0.25)$ & 1.41 & 1.74 & 47 & 0.37 & 0.36 \\
\hline Thick snow & $2.50(1.10)$ & $0.60(0.25)$ & 1.37 & 1.98 & 48 & 0.38 & 0.37 \\
\hline Thin snow & $2.50(1.10)$ & $0.20(0.25)$ & 1.42 & 1.68 & 45 & 0.34 & 0.35 \\
\hline Rough snow & $2.50(1.10)$ & $0.30(0.40)$ & 1.41 & 1.81 & 46 & 0.36 & 0.38 \\
\hline Smooth snow & $2.50(1.10)$ & $0.30(0.10)$ & 1.39 & 1.68 & 49 & 0.36 & 0.33 \\
\hline Rough ice & $3.40(1.50)$ & $0.30(0.25)$ & 1.67 & 1.73 & 47 & 0.31 & 0.33 \\
\hline Smooth ice & $2.50(0.50)$ & $0.30(0.25)$ & 1.23 & 1.82 & 53 & 0.36 & 0.30 \\
\hline High permeability & $2.50(1.10)$ & $0.30(0.25)$ & 1.42 & 1.76 & 43 & 0.31 & 0.30 \\
\hline Low permeability & $2.50(1.10)$ & $0.30(0.25)$ & 1.61 & 1.95 & 70 & 0.19 & 0.57 \\
\hline
\end{tabular}

\footnotetext{
${ }^{\mathrm{a}}$ Ablation is expressed as a decrease in mean thickness across the whole domain.
}

${ }^{\mathrm{b}}$ Standard deviations given in parentheses. 
ability for first-year ice and multiyear ice. Unless otherwise indicated, all parameters are the same as for the appropriate standard case. As for the standard cases, the model runs start on 20 May (day 140) and run for 90 days with a time step of $1 \mathrm{~h}$. Tables 2 and 3 summarize the important results for the sensitivity studies (and the standard cases for reference) for first-year ice and multiyear ice, respectively. FYI denotes first-year sea ice and MYI denotes multiyear sea ice.

\subsection{First-Year Ice Sensitivity Studies 4.1.1. Sensitivity of FYI Pond Coverage to the Snow Cover}

[58] The following studies examine the sensitivity of pond evolution and ablation to snow depth and roughness. Snow provides the initial meltwater from which ponds form and is therefore important to pond fraction at the start of the melt season.

\subsubsection{FYI: Thick Snow}

[59] The mean snow thickness here is $0.5 \mathrm{~m}$ which is a realistic snow thickness for first-year ice, based on observations by Sturm et al. [2002]. The first snow cells melt through on day 176, 9 days later than in the standard firstyear ice case (see Figure 10). The increase in water volume generated by ice melt causes the water surface to become flooded with large ponds, at maximum extent $94 \%$ of the surface is covered with ponds. Mean individual pond area at this time is $12533 \mathrm{~m}^{2}$ (see Figure 12) which is a third of the area of the grid.

[60] Due to the large volume of water generated early in the season ponds remain even as horizontal permeability increases, since enhanced melting beneath ponds causes more radiation to be absorbed and melt ponds to deepen. This eventually leads to ice cells melting through and an increase in ocean fraction, by the end of the simulation $95 \%$ of the surface is open ocean.

[61] A significant result of this study is the total decrease in ice and snow mass is $96 \%$ compared to $62 \%$ in the standard case, despite there being a greater initial mass in the thick snow case. To put this another way, an additional $0.19 \mathrm{~m}$ of snow at the beginning of the melt season caused an increase in ice and snow ablation of $0.82 \mathrm{~m}$, averaged over the whole domain, due to the enhanced albedo feedback mechanism.

\subsubsection{FYI: Thin Snow}

[62] The snow topography here represents the snow cover found on thin ice [Sturm et al., 2002]. The topography was generated using a mean snow depth of $0.2 \mathrm{~m}$, which resulted in some grid cells having a negative snow thickness. The snow thickness on these cells was set to zero thickness, which resulted in the average snow depth over the domain being increased to $0.24 \mathrm{~m}$. Mean snow depth is $0.31 \mathrm{~m}$ in the standard case. Although snow cover is thinner on average, snow is removed from the ice surface in the thin snow case within a few hours of the standard case (see Figure 11), but due to the smaller volume of water generated by the melted snow, pond fraction (Figure 11) and mean pond area (Figure 12) are smaller than the standard case. Mean snow depth is determined by the mean depth of snow in all cells with a snow cover. Therefore melting of the thinnest snow can result in increases in the mean snow depth, as can be seen in Figure 11 around day 167. The maximum pond fraction reached is $38 \%$ compared with $49 \%$ in the standard case. The evolution of pond fraction and area (Figures 11 and 12) is similar to the standard case, which is indicative of the controlling role of the underlying ice topography.

\subsubsection{FYI: Rough Snow}

[63] The snow topography used here represents the snow cover that would be expected on hummocky ice [Sturm et al., 2002], the standard deviation is increased from $0.15 \mathrm{~m}$ for the standard case to $0.25 \mathrm{~m}$. Mean snow depth in the standard case was $0.31 \mathrm{~m}$ and in this case is $0.34 \mathrm{~m}$ due to an imposed nonzero snow depth. Altering the roughness of the snow had only a marginal effect on mean pond depth and the fraction of the surface covered in ponds (not shown). There was a slight increase in the surface fraction covered in ponds, with maximum pond fraction increasing from $49 \%$ to $54 \%$. There was an increase in maximum mean pond area from $219 \mathrm{~m}^{2}$ in the standard case to $315 \mathrm{~m}^{2}$ in the rough snow case and mean pond area (Figure 12) exceeds the standard case pond area between days 185 and 195, when pond fraction is at its greatest. Total ice and snow ablation in the rough snow case at $1.45 \mathrm{~m}$ is greater than $1.33 \mathrm{~m}$ in the standard case, although increase in ablation is more likely to be due to the slight increase in mean snow depth than the variation in snow roughness.

\subsubsection{FYI: Smooth Snow}

[64] The standard deviation in snow depth in the smooth snow case was reduced from $0.15 \mathrm{~m}$ to $0.1 \mathrm{~m}$ which is the standard deviation in snow depth observed on thin ice by Sturm et al. [2002]. The smooth snow case differs from the standard first-year ice case most obviously at the start of the season as the smaller variability in snow depth results in snow melting at the same rate across the grid causing initial pond fraction (not shown) and mean pond area (see Figure 12) to be greater than the standard case. However, some of the ponds that form early in the season drain away as permeability increases so that pond fraction is indistinguishable from the standard case after day 180 and total ablation in the standard case and the smooth snow case are very similar, $1.33 \mathrm{~m}$ and $1.31 \mathrm{~m}$, respectively.

[65] The impact of reducing the variability in thickness of the snow cover was only evident at the start of the season and appears to have almost no impact on ice ablation or pond fraction.

Figure 10. First-year ice, thick snow case. (top) Variation in the fractional distribution of surface area with time for the thick snow case, where mean ice thickness is $1.70 \mathrm{~m}$, standard deviation in ice thickness is $0.20 \mathrm{~m}$, mean snow thickness is $0.50 \mathrm{~m}$, and standard deviation in snow thickness is $0.10 \mathrm{~m}$. Fraction of the surface with a snow cover is light blue, fraction of the surface covered with melt ponds is red, and fraction of the surface with no ice cover (open ocean) is dark blue. The dashed lines represent the corresponding values for the standard first-year ice case. (bottom) Change in mean snow depth (light blue), mean pond depth (red), and mean ice thickness (black) with time for the thick snow case. The dashed lines represent the corresponding values for the standard first-year ice case. 

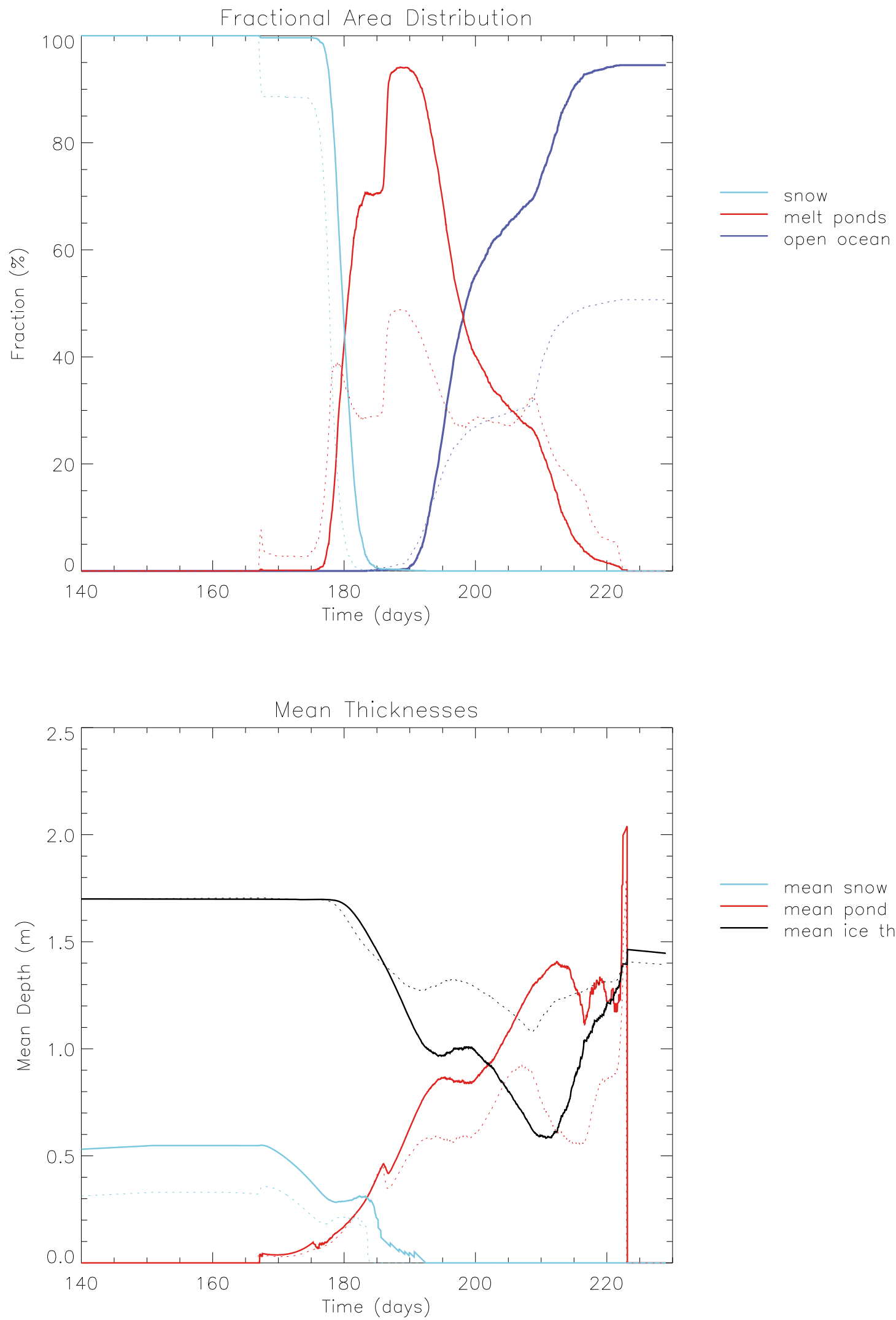

mean snow thickness

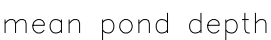

mean ice thickness

Figure 10 

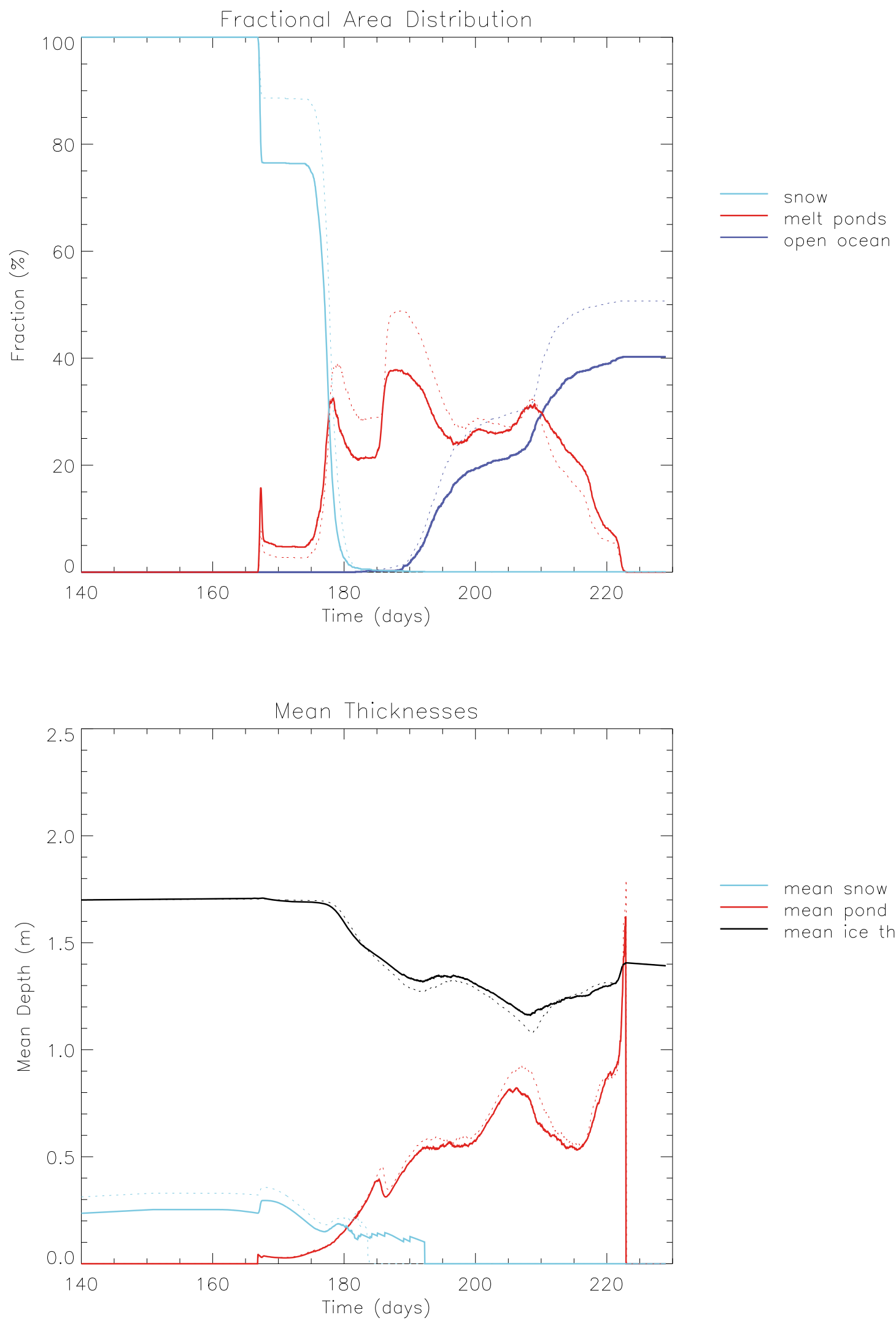

mean snow thickness

mean pond depth

mean ice thickness

Figure 11

18 of 37 


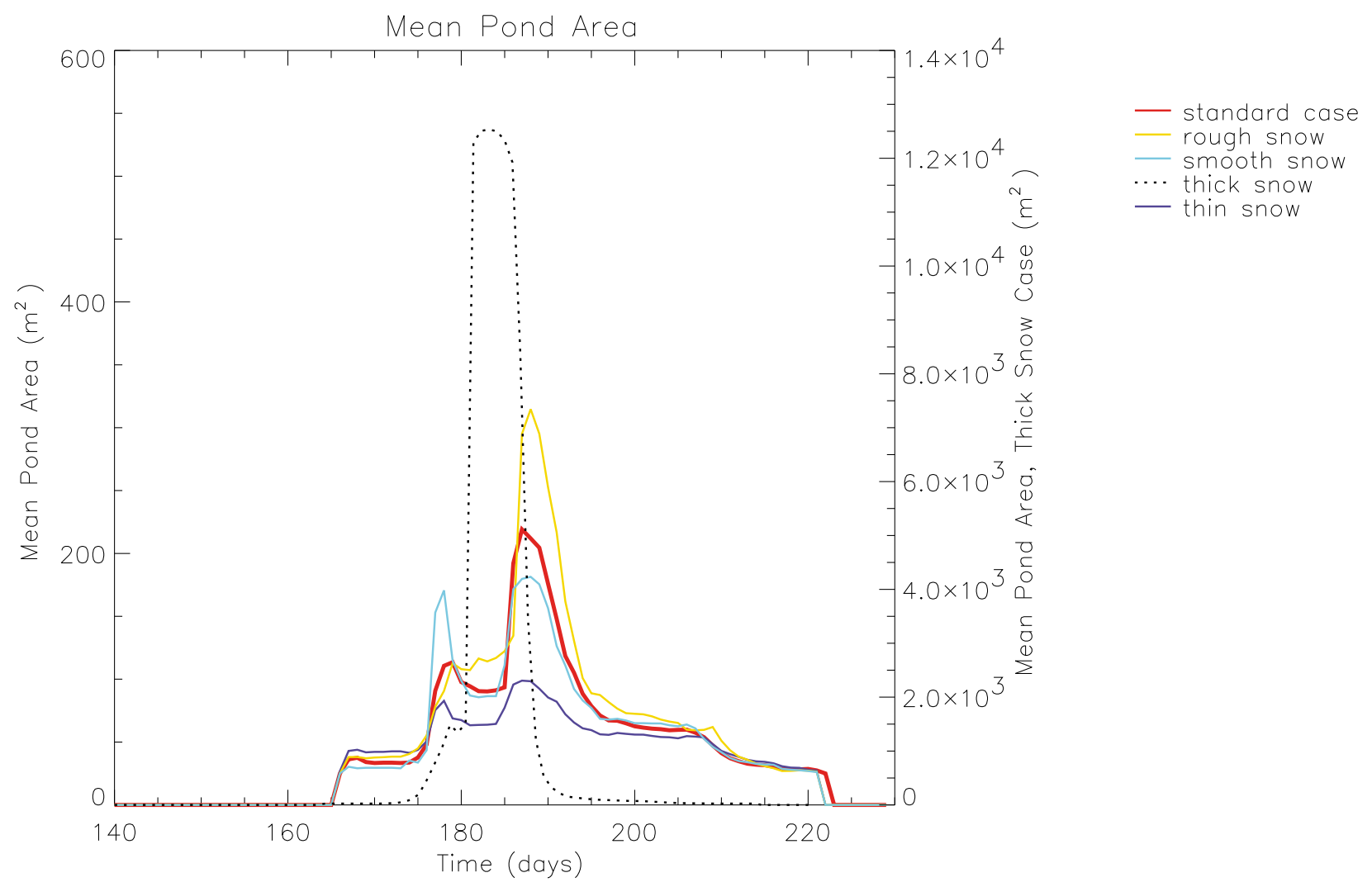

Figure 12. First-year ice. Mean individual pond area for the standard case (red) and snow sensitivity studies. Scale for the thick snow case (dotted black) is given on the right-hand axis.

\subsubsection{Sensitivity of FYI Pond Coverage to Ice Topography \\ 4.1.2.1. FYI: Rough Ice}

[66] The initial mean ice thickness here was $1.7 \mathrm{~m}$ and the standard deviation in ice thickness was increased from $0.2 \mathrm{~m}$ in the standard case to $0.5 \mathrm{~m}$ which is the standard deviation in ice thickness observed on smooth multiyear ice during the SHEBA field survey [Perovich et al., 1999]. Figure 13 shows snow cover being removed at a slightly different rate to the standard first-year ice simulation, this is because the snow melt rate depends on the temperature at the snowice interface which varies with ice depth. Initial ponds form at the same time in the standard case and the rough ice case, but the rough ice case consistently has a higher fraction of the surface covered in ponds compared to the standard case, with a maximum of $56 \%$. This is due to there being a greater number of cells having a surface height below sea level in the rough ice case and because ponds cannot drain unless their surface height is above sea level. The maximum mean pond area is $314 \mathrm{~m}^{2}$, shown in Figure 15, which is greater that $219 \mathrm{~m}^{2}$ in the standard case; the extra surface water leads to the mean albedo (Figure 26) being lower than the standard case, particularly toward the end of the season when more cells are open ocean.

\subsubsection{FYI: Smooth Ice}

[67] The standard deviation in ice thickness here is 0.02 $\mathrm{m}$, which is the standard deviation in ice thickness calculated from SHEBA measurements of young, smooth ice [Perovich et al., 1999]. Figure 14 shows that the difference in pond evolution compared to the standard first-year ice case is substantial. Whilst ponds initially form on day 167 , the same time as the standard case, because most of the ice surface is above sea level and the ice is sufficiently permeable the snow melt drains immediately through the ice. A persistent pond cover does not occur until day 185 when surface melt rates have increased and enhanced melting can take place beneath ponds, creating depressions in the ice surface where pools of water can collect. The delay in pond

Figure 11. First-year ice, thin snow case. (top) Variation in the fractional distribution of surface area with time for the thin snow case, where mean ice thickness is $1.70 \mathrm{~m}$, standard deviation in ice thickness is $0.20 \mathrm{~m}$, mean snow thickness is 0.24 $\mathrm{m}$, and standard deviation in snow thickness is $0.15 \mathrm{~m}$. Fraction of the surface with a snow cover is light blue, fraction of the surface covered with melt ponds is red, and fraction of the surface with no ice cover (open ocean) is dark blue. The dashed lines represent the corresponding values for the standard first-year ice case. (bottom) Change in mean snow depth (light blue), mean pond depth (red), and mean ice thickness (black) with time for the thin snow case. The dashed lines represent the corresponding values for the standard first-year ice case. 

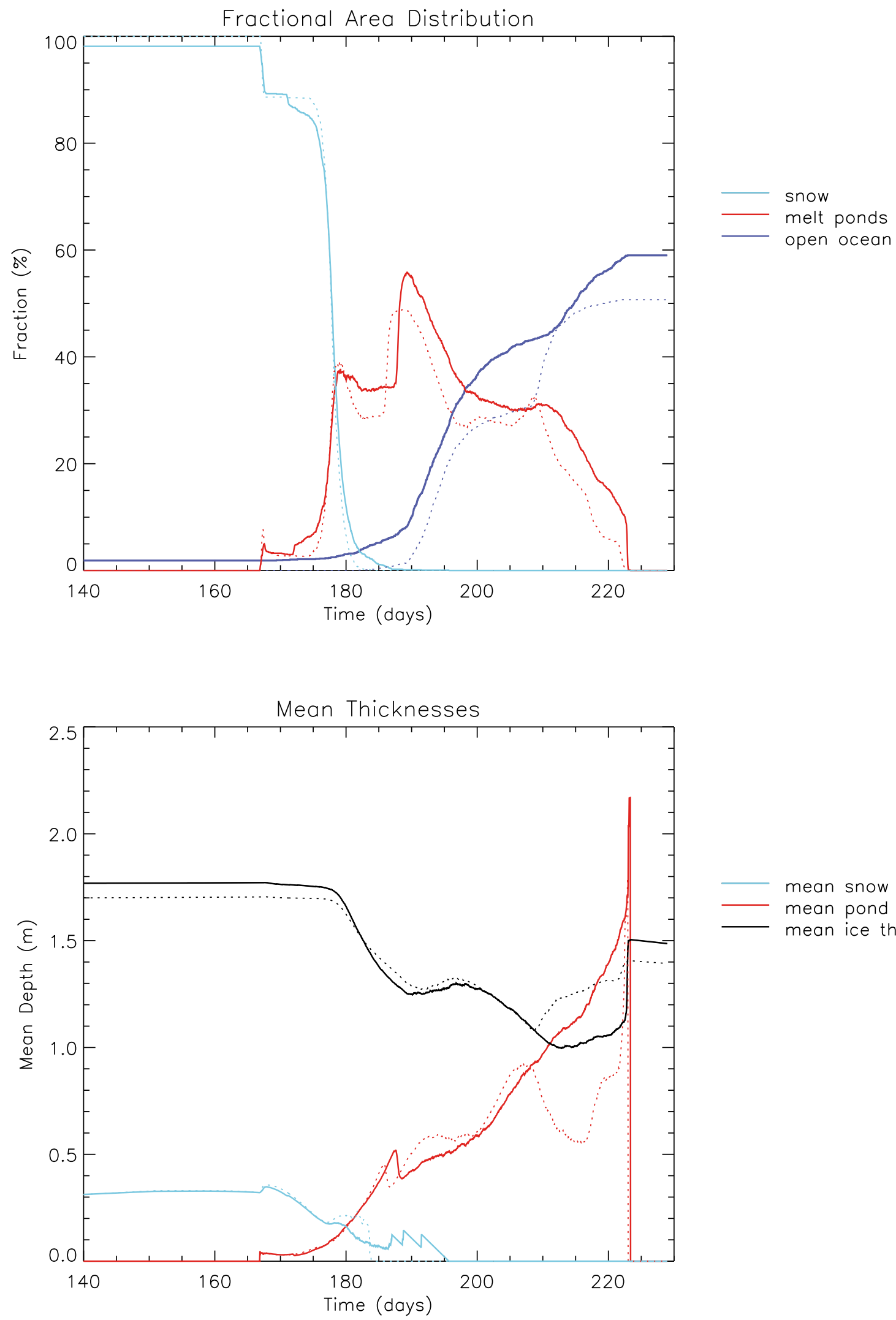

mean snow thickness

mean pond depth

mean ice thickness

Figure 13 
formation also has an impact on pond depth, with mean pond depth being lower than the standard case. Pond coverage is still increasing after day 210 , whereas at the same time in the standard case pond cover is decreasing as ponds have begun to melt through to the ocean. Maximum mean pond area shown in Figure 15 is $99 \mathrm{~m}^{2}$ which is less than half the size of the mean pond area in the standard case. Despite these differences maximum pond coverage is $50 \%$, which is greater than the standard case. However the lack of enhanced melting early in the season means that total ice ablation is only $0.39 \mathrm{~m}$, much lower than $1.01 \mathrm{~m}$ in the standard case.

[68] The mean surface albedo (Figure 26) has more variation than all the other cases due to the variation in pond coverage, which agrees with results reported by Eicken et al. [2004, Table 1]. Due to the very small number of open ocean cells the mean albedo of the domain is greater than the standard case throughout the season, including when pond coverage is at its maximum.

\subsubsection{Sensitivity of FYI Pond Coverage to Permeability}

[69] Permeability was increased and decreased by a factor of ten from the standard case. Permeability is difficult to measure and there is much uncertainty about this parameter [Eicken et al., 2004], so the permeabilities were chosen to span the range of observational uncertainty so that the impact of permeability on pond evolution could be examined.

\subsubsection{FYI: High Permeability}

[70] Vertical ice permeability was increased from $2.4 \times$ $10^{-12} \mathrm{~m}^{2}$ in the standard case to $2.4 \times 10^{-11} \mathrm{~m}^{2}$; for the same hydraulic head, this increases the rate of vertical drainage through the ice by a factor of 10 . Maximum pond fraction compared to the standard case is reduced to $44 \%$ from $49 \%$ and only $45 \%$ of ice cells melt through compared to $51 \%$ in the standard case. Mean pond depth is similar to the standard case throughout the season and maximum mean individual pond area is slightly less at $150 \mathrm{~m}^{2}$ compared to 219 $\mathrm{m}^{2}$ in the standard case.

\subsubsection{FYI: Low Permeability}

[71] Vertical ice permeability was reduced from $2.4 \times$ $10^{-12} \mathrm{~m}^{2}$ to $2.4 \times 10^{-13} \mathrm{~m}^{2}$; for the same hydraulic head, this reduces the rate of vertical drainage through the ice by a factor of ten. Figure 16 shows pond fraction increasing rapidly to $91 \%$ as the snow cover melts away, the high pond fraction remains for 10 days before gradually decreasing as ice cells melt through, providing a drain for surface meltwater. The maximum mean pond area, shown in Figure 17, is $36275 \mathrm{~m}^{2}$ which is several orders of magnitude greater than the maximum mean pond area in the standard case. Mean pond area remains greater than mean pond area in the standard case, even as ice cells melt through, due to the majority of the ice surface being flooded with meltwater.
[72] The decrease in total ice and snow volume is $91 \%$ compared to $62 \%$ in the standard case. Total ice ablation exceeds the standard case by more than $50 \mathrm{~cm}$, which is due to the increased presence of surface water that enhances the rate of melting of the ice beneath.

\subsection{Multiyear Ice Sensitivity Studies 4.2.1. Sensitivity of MYI Pond Coverage to the Snow Cover}

\subsubsection{MYI: Thick Snow}

[73] The mean snow thickness of $0.6 \mathrm{~m}$ used here is that observed on deformed ice, following Sturm et al. [2002]. Some ponds form on day 167, as in the standard case (not shown), and the majority of ice cells are exposed 3 days later. In the first-year ice thick snow case snow is totally removed 9 days later than the first-year ice standard case; such a delay in removing snow cover is not observed in the multiyear ice thick snow case because of the ice topography. The multiyear ice topography has steeper gradients between cells that causes snow melt to collect rapidly in topographic lows, saturating snow in these regions which then melts at an accelerated rate.

[74] In this case the additional surface water at the start of the season has no impact on pond fraction later in the season. Maximum pond fraction and maximum mean pond area (Figure 18) are similar to the standard case, $48 \%$ compared with $47 \%$ and $151 \mathrm{~m}^{2}$ compared with $147 \mathrm{~m}^{2}$. This is in part due to the limitations on the locations where ponds can form. Ponds form in the deep depressions and pond water is unable to travel far across the surface, so ponds in this case tend to be of small area and deep. This is different to the first-year ice thick snow case where the surface is flooded with snow melt, creating a large pond area fraction. Total ice and snow ablation is $0.24 \mathrm{~m}$ greater than the standard case. 4.2.1.2. MYI: Thin Snow

[75] The mean snow thickness here is $0.20 \mathrm{~m}$ which is the snow thickness that would be expected on thin multiyear ice [Sturm et al., 2002]. There is very little variation in the development of ponds compared to the multiyear ice standard case. Snow cover melts away entirely a few hours before the standard case (not shown), which causes the maximum pond fraction to be reached a few hours before the standard case. The reduction in available surface water reduces maximum pond fraction to $45 \%$ from $47 \%$ and slightly reduces maximum mean pond area. Apart from this the main impact of the variation in snow cover is at the start of the melt season when mean ice thickness decreases in advance of the standard case due to ice cells being exposed to enhanced melting earlier in the season. The total ice ablation is reduced by $6 \mathrm{~cm}$ compared to the standard case.

Figure 13. First-year rough ice case. (top) Variation in the fractional distribution of surface area with time for the rough ice case, where mean ice thickness is $1.70 \mathrm{~m}$, standard deviation in ice thickness is $0.50 \mathrm{~m}$, mean snow thickness is $0.30 \mathrm{~m}$, and standard deviation in snow thickness is $0.15 \mathrm{~m}$. Fraction of the surface with a snow cover is light blue, fraction of the surface covered with melt ponds is red, and fraction of the surface with no ice cover (open ocean) is dark blue. The dashed lines represent the corresponding values for the standard first-year ice case. (bottom) Change in mean snow depth (light blue), mean pond depth (red), and mean ice thickness (black) with time for the rough ice case. The dashed lines represent the corresponding values for the standard first-year ice case. 

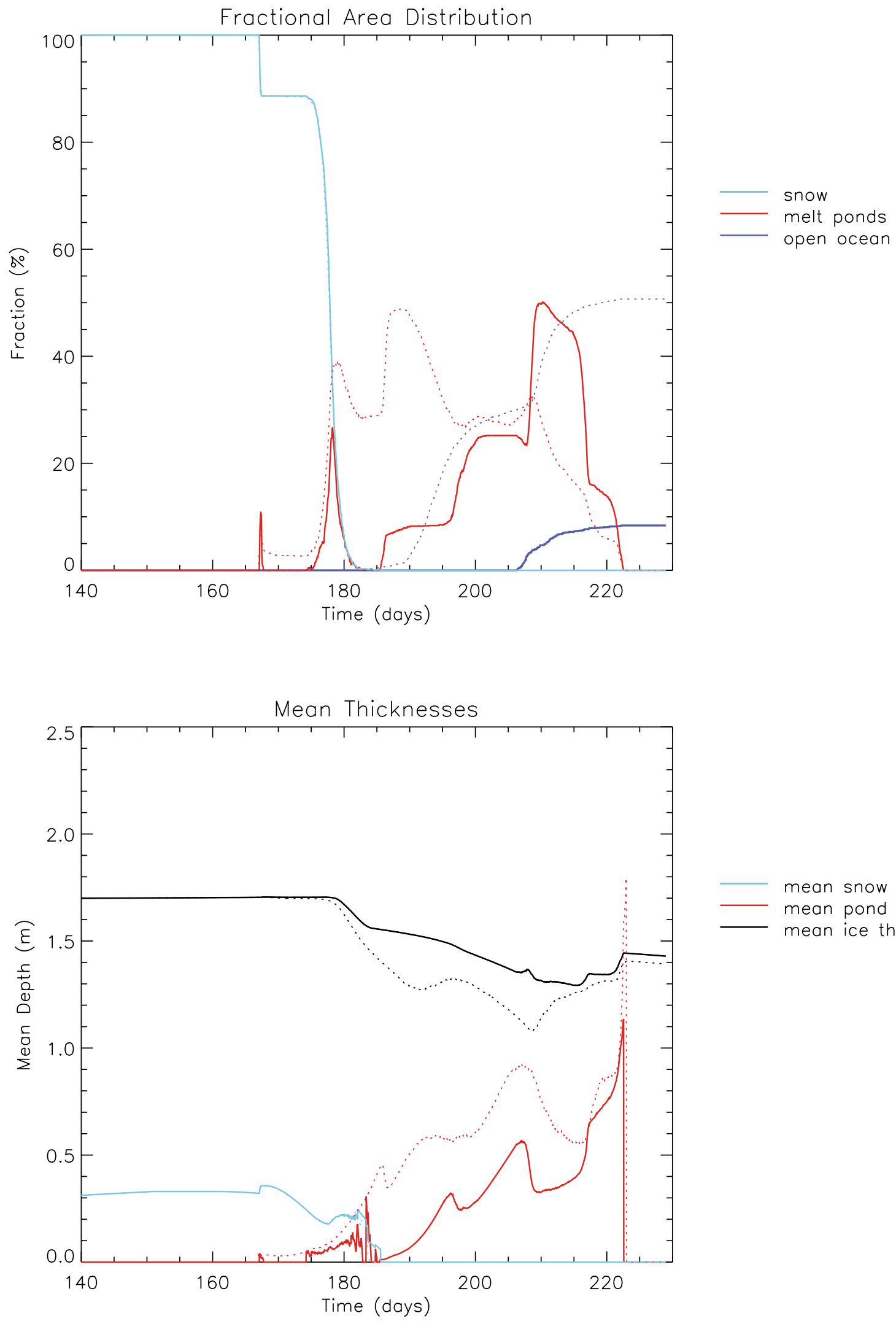

mean snow thickness

mean pond depth

mean ice thickness

Figure 14 


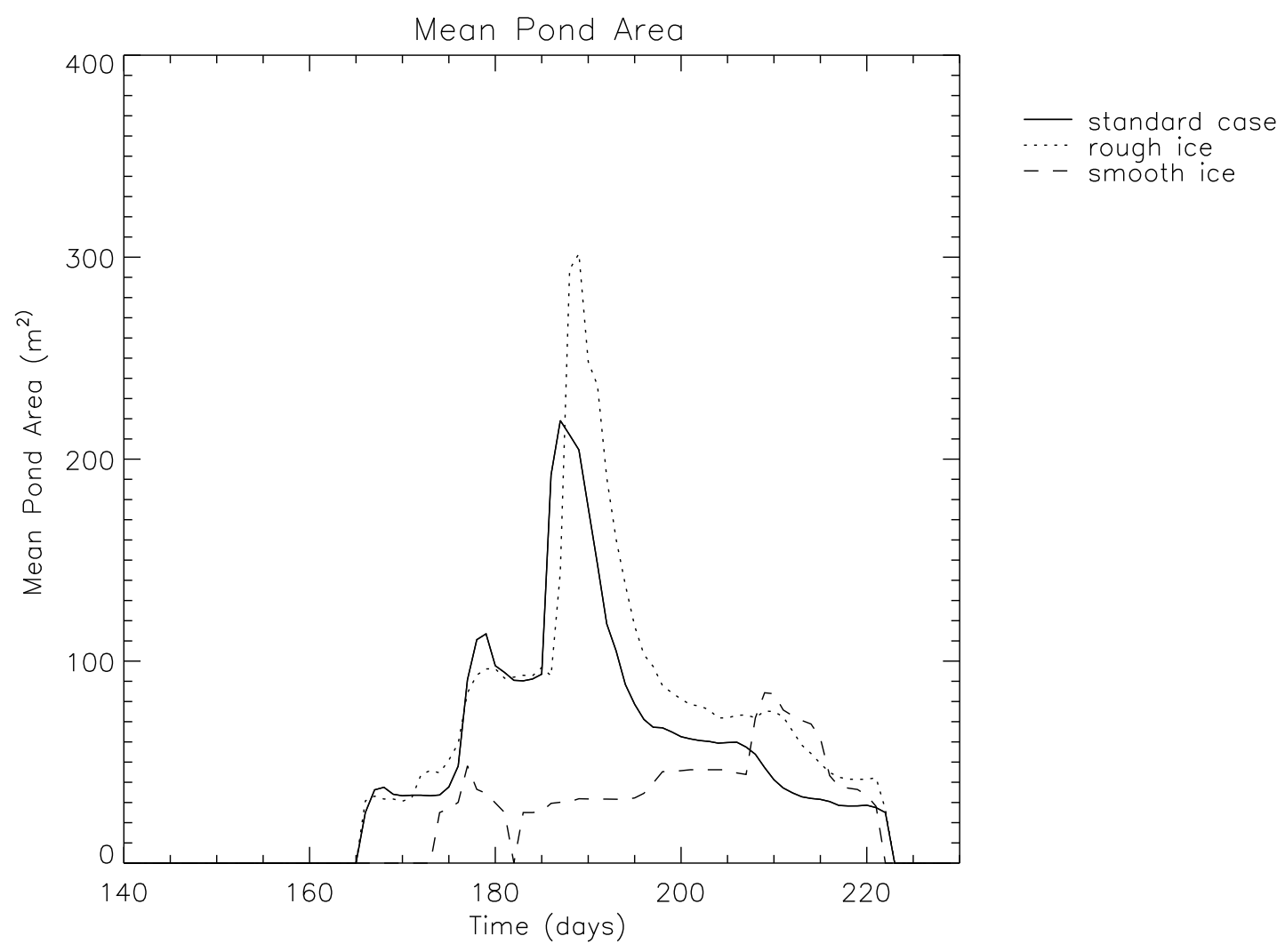

Figure 15. First-year ice. Mean individual pond area for the standard case and snow sensitivity studies.

\subsubsection{MYI: Rough Snow}

[76] The standard deviation in snow thickness here was $0.4 \mathrm{~m}$, compared with $0.25 \mathrm{~m}$ in the standard case, and would be expected on deformed multiyear ice [Sturm et al., 2002]. There is very little difference between this case and the standard case, the main differences occur early in the season when the extra variability in snow thickness causes the snow cover to melt through completely 3 days later than the standard case which delays the occurrence of the maximum pond fraction. This demonstrates that ponds are forming at all available locations and due to the presence of many local minima in ice height water is unable to travel far across the surface.

\subsubsection{MYI: Smooth Snow}

[77] Here the standard deviation in snow depth is $0.10 \mathrm{~m}$ compared with $0.25 \mathrm{~m}$ in the standard case, which is the standard deviation in snow thickness observed on thin ice by Sturm et al. [2002] and is used in the first-year ice standard case. Similar to the rough snow case there was very little difference in pond fraction and mean pond area compared to the standard case. The only differences are at the start of the season due to snow cover being removed earlier in the smooth snow case. There is no substantial difference in ice melt and mean pond depth is smaller than in the standard case.

\subsubsection{Sensitivity of MYI Pond Coverage to Ice Topography} 4.2.2.1. MYI: Rough Ice

[78] The mean initial ice thickness across the entire grid in this case is $2.5 \mathrm{~m}$, the same as the standard case, however since the greater variability in ice thickness causes some cells to have a zero ice thickness then, once these cells are excluded from the calculation, the actual mean ice thickness is $3.4 \mathrm{~m}$. The standard deviation in this case is $1.5 \mathrm{~m}$ which is the standard deviation in ice thickness expected on deformed ice [Lüthje et al., 2006]. The fractional distribution of area types and change in mean depths are shown in Figure 19. Since water collects in deeper depressions or is

Figure 14. First-year smooth ice case. (top) Variation in the fractional distribution of surface area with time for the smooth ice case, where mean ice thickness is $1.70 \mathrm{~m}$, standard deviation in ice thickness is $0.02 \mathrm{~m}$, mean snow thickness is $0.30 \mathrm{~m}$, and standard deviation in snow thickness is $0.15 \mathrm{~m}$. Fraction of the surface with a snow cover is light blue, fraction of the surface covered with melt ponds is red, and fraction of the surface with no ice cover (open ocean) is dark blue. The dashed lines represent the corresponding values for the standard first-year ice case. (bottom) Change in mean snow depth (light blue), mean pond depth (red), and mean ice thickness (black) with time for the smooth ice case. The dashed lines represent the corresponding values for the standard first-year ice case. 

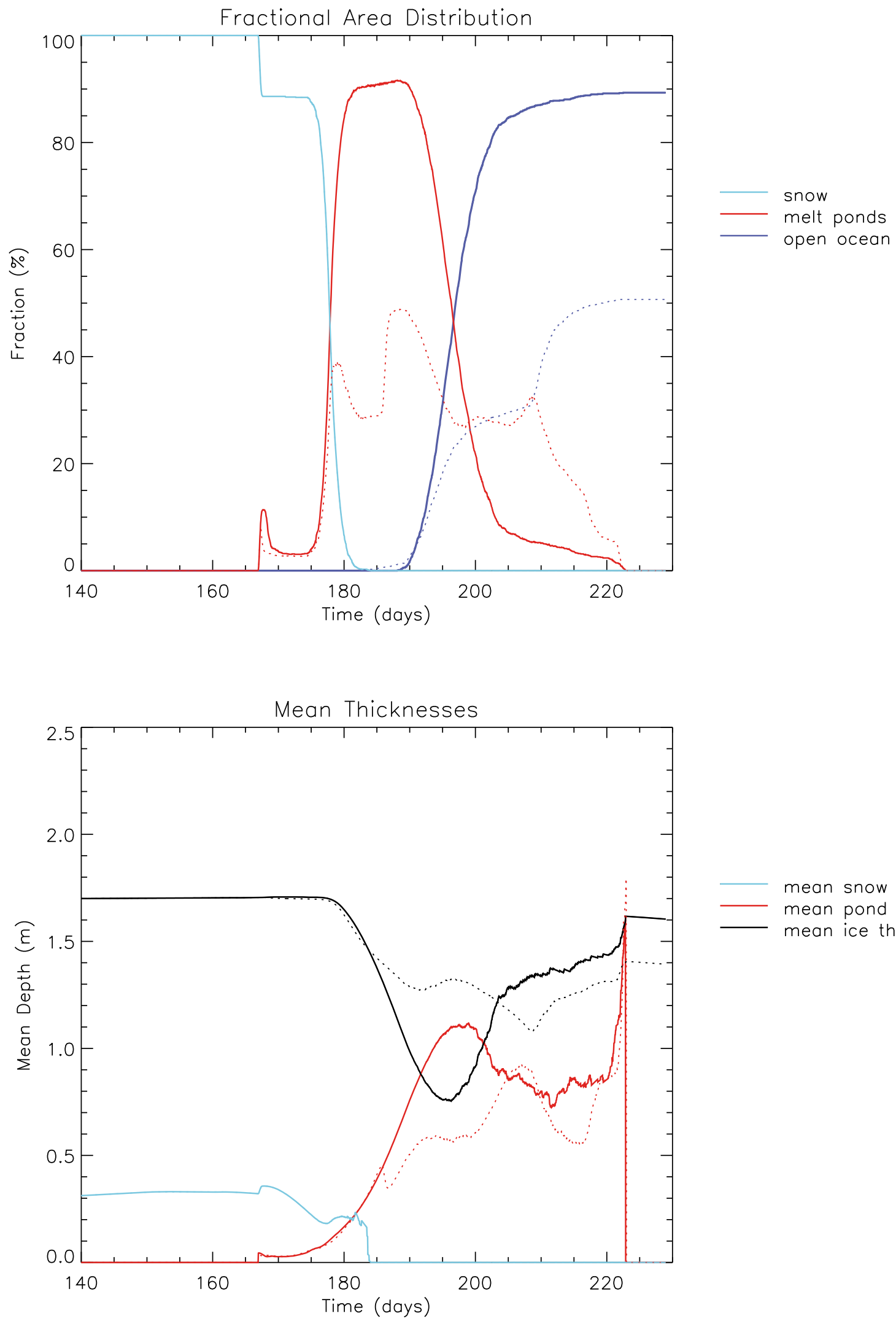

mean snow thickness

mean pond depth

mean ice thickness

Figure 16 


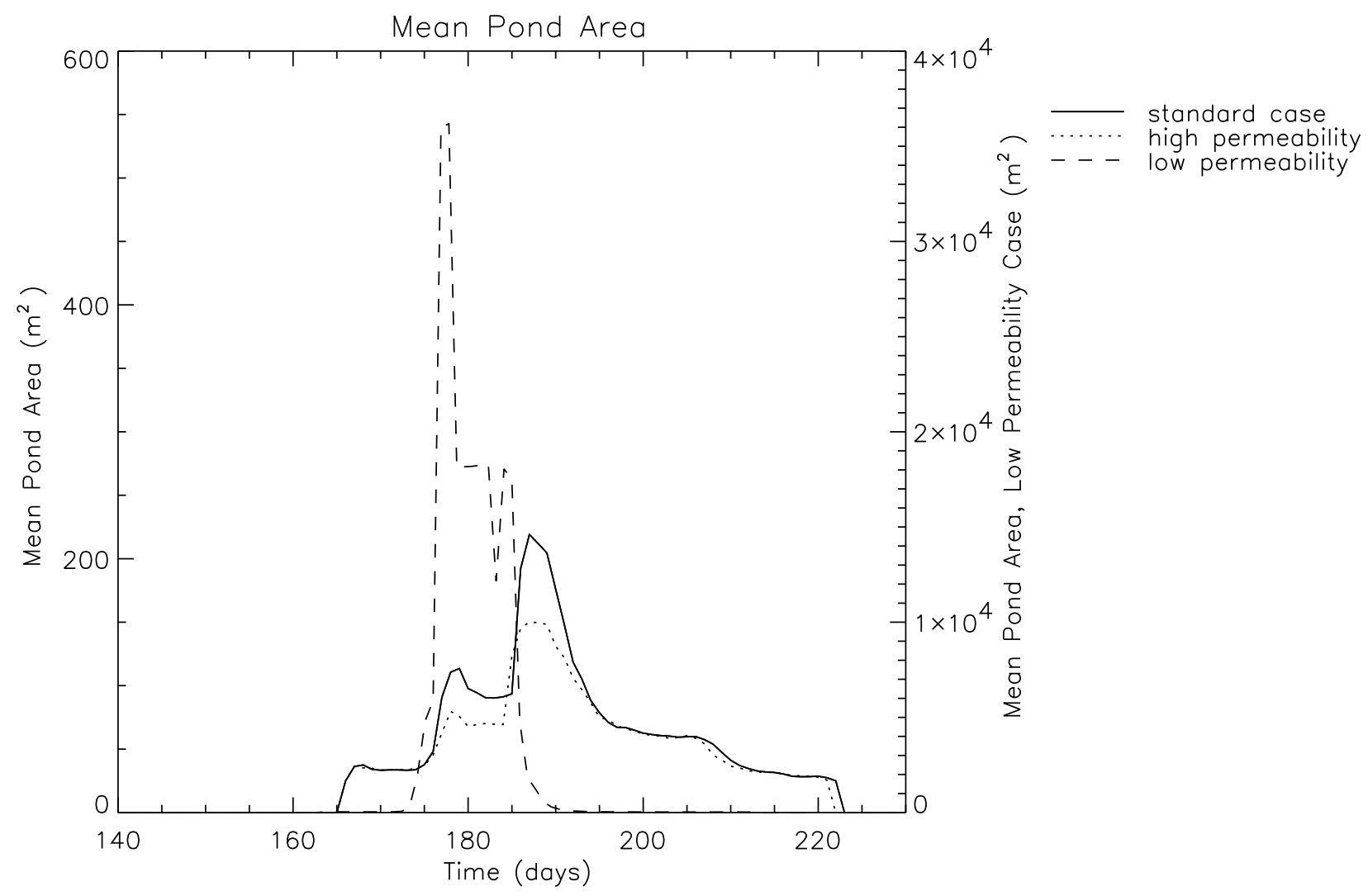

Figure 17. First-year ice. Mean individual pond area for the standard case and snow sensitivity studies. Scale for the low-permeability case (dashed line) is on the right-hand axis.

lost to the ocean there is very little difference in pond fraction, pond depth or mean pond area (Figure 21) between the multiyear rough ice case and the standard multiyear ice case. Total snow and ice ablation is $1.73 \mathrm{~m}$ which is $1 \mathrm{~cm}$ less than the standard case and maximum pond fraction in both cases is identical. Due to the greater initial ocean fraction here the mean surface albedo shown in Figure 29 is consistently lower than the standard case.

\subsubsection{MYI: Smooth Ice}

[79] The mean ice thickness in this case is $2.5 \mathrm{~m}$ and the standard deviation in ice thickness is $0.5 \mathrm{~m}$, which is the same standard deviation as the first-year rough ice case discussed in section 4.1.2.1. The fractional distribution of area types and change in mean depths are shown in Figure 20. Like the first-year rough ice case the multiyear smooth ice case reaches its maximum pond fraction of $53 \%$ on day 196 later in the season, rather than immediately after the snow cover is removed. The lower pond fraction earlier in the season compared to the standard case is due to there being fewer regions below sea level where ponds can form, until enhanced melting beneath ponds has developed deeper depressions. Whilst the maximum pond fraction reached is greater than in the standard case the mean surface albedo in the smooth ice case is higher than the standard case because the smooth ice case has no cells that are initially open ocean. The smooth ice case allows surface water to spread further, thus maximum mean pond area is $255 \mathrm{~m}^{2}$ compared with $147 \mathrm{~m}^{2}$ in the standard case (Figure 21). Mean pond areas are comparable with first-year ice values.

\subsubsection{Sensitivity of MYI Pond Coverage}

to Permeability

\subsubsection{MYI: High Permeability}

[80] Vertical ice permeability was increased from $2.4 \times$ $10^{-12} \mathrm{~m}^{2}$ to $2.4 \times 10^{-11} \mathrm{~m}^{2}$, as in the first-year ice case. Surface water causes the ice below it to melt at a faster rate than bare ice. The reduction of surface water here due to the high-permeability results in fewer ice cells melting through entirely leading to the final ocean fraction being $6 \%$ lower

Figure 16. First-year ice, low-permeability case. (top) Variation in the fractional distribution of surface area with time for the alternative low-permeability case, where mean ice thickness is $1.70 \mathrm{~m}$, standard deviation in ice thickness is $0.20 \mathrm{~m}$, mean snow thickness is $0.31 \mathrm{~m}$, and standard deviation in snow thickness is $0.15 \mathrm{~m}$. Fraction of the surface with a snow cover is light blue, fraction of the surface covered with melt ponds is red, and fraction of the surface with no ice cover (open ocean) is dark blue. The dashed lines represent the corresponding values for the standard first-year ice case. (bottom) Change in mean snow depth (light blue), mean pond depth (red), and mean ice thickness (black) with time for the low-permeability case. The dashed lines represent the corresponding values for the standard first-year ice case. 


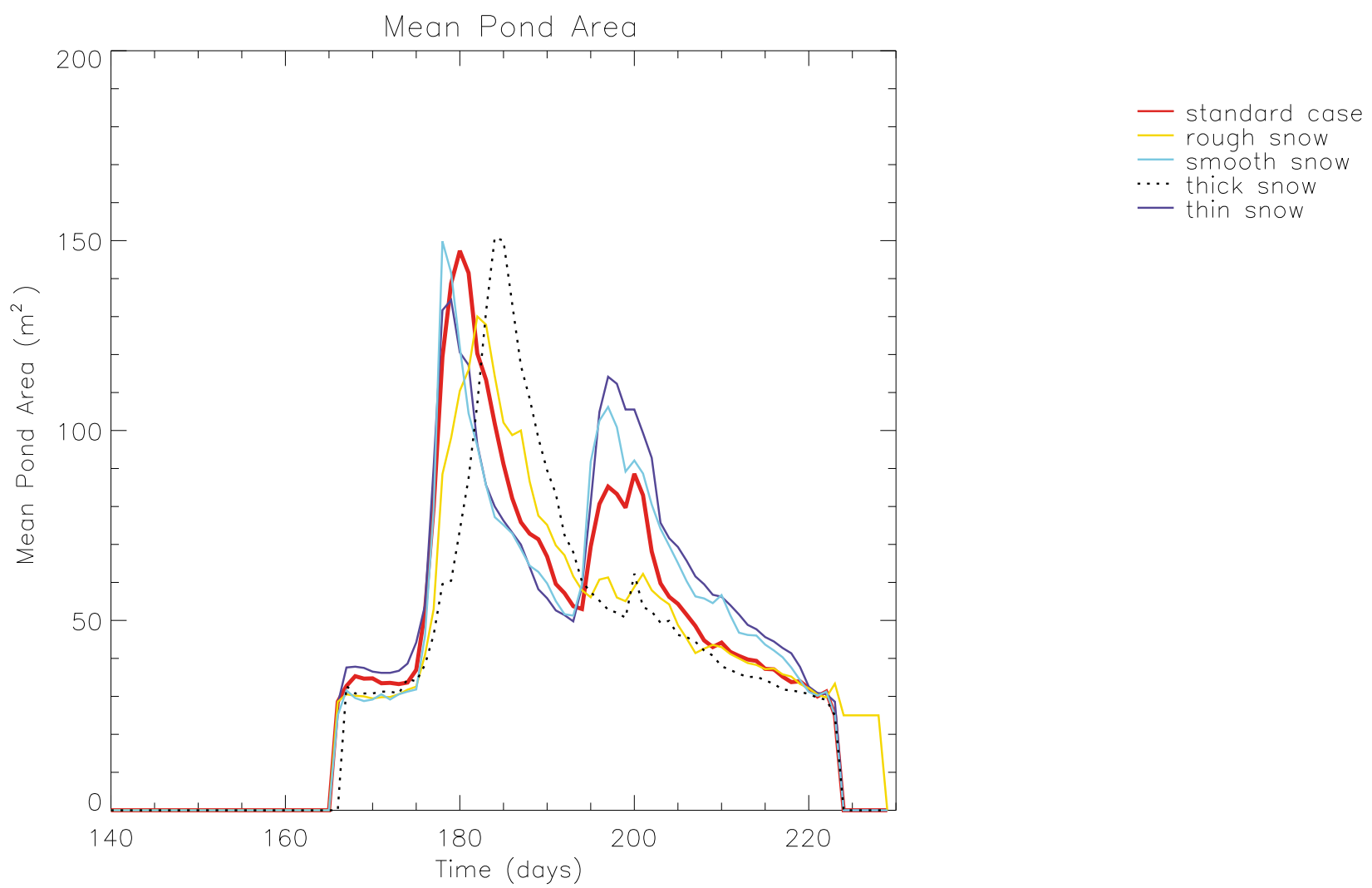

Figure 18. Multiyear ice case. Mean individual pond area for the standard case and snow sensitivity studies.

than the standard case. The reduction in open ocean cells, which provide drainage areas for surface water, causes mean pond area in the high-permeability case (Figure 24) to exceed that in the standard case in the latter half of the season. Mean pond depth is lower in the high-permeability study, although total snow and ice ablation is similar with $1.76 \mathrm{~m}$ in the standard case and $1.74 \mathrm{~m}$ in the highpermeability case. Figure 23 shows ponds draining more rapidly than the standard case and thus a maximum pond fraction of $43 \%$ is reached later in the season than the standard multiyear ice case, between days 188 and 192, when melt rates exceed drainage rates.

\subsubsection{MYI: Low Permeability}

[81] As in the first-year ice case, vertical ice permeability was reduced from $2.4 \times 10^{-12} \mathrm{~m}^{2}$ to $2.4 \times 10^{-13} \mathrm{~m}^{2}$, this resulted in an increase in the area covered in ponds and an increase in mean pond depth (shown in Figure 22). Maximum pond fraction is $70 \%$ in the low-permeability case compared with $47 \%$ in the multiyear ice standard case. The additional surface water caused an increase in mean pond area, shown in Figure 24, from $147 \mathrm{~m}^{2}$ in the standard case to $1067 \mathrm{~m}^{2}$ in the low-permeability case. Although the ponds are much larger, the ice surface does not become flooded with water as was the cases in the first-year ice lowpermeability case, which is because pond size is dictated by the ice surface topography. The greater volume of surface water caused a reduction in mass of $61 \%$ compared with $54 \%$ in the standard case.

\subsection{Discussion of Sensitivity Studies}

[82] Tables 2 and 3 summarize the important results for the standard case runs and the sensitivity studies presented in this paper.

[83] With the exception of the first-year ice thick snow case the impact of altering the snow cover was evident mainly at the start of the season since the snow cover is the water source for the initial formation of ponds. In our model, vertical drainage of snow meltwater through the sea ice is

Figure 19. Multiyear rough ice case. (top) Variation in the fractional distribution of surface area with time for the rough ice case, where mean ice thickness is $3.40 \mathrm{~m}$, standard deviation in ice thickness is $1.50 \mathrm{~m}$, mean snow thickness is $0.30 \mathrm{~m}$, and standard deviation in snow thickness is $0.25 \mathrm{~m}$. Fraction of the surface with a snow cover is light blue, fraction of the surface covered with melt ponds is red, and fraction of the surface with no ice cover (open ocean) is dark blue. The dashed lines represent the corresponding values for the standard multiyear ice case. (bottom) Change in mean snow depth (light blue), mean pond depth (red), and mean ice thickness (black) with time for the rough ice case. The dashed lines represent the corresponding values for the standard multiyear ice case. 

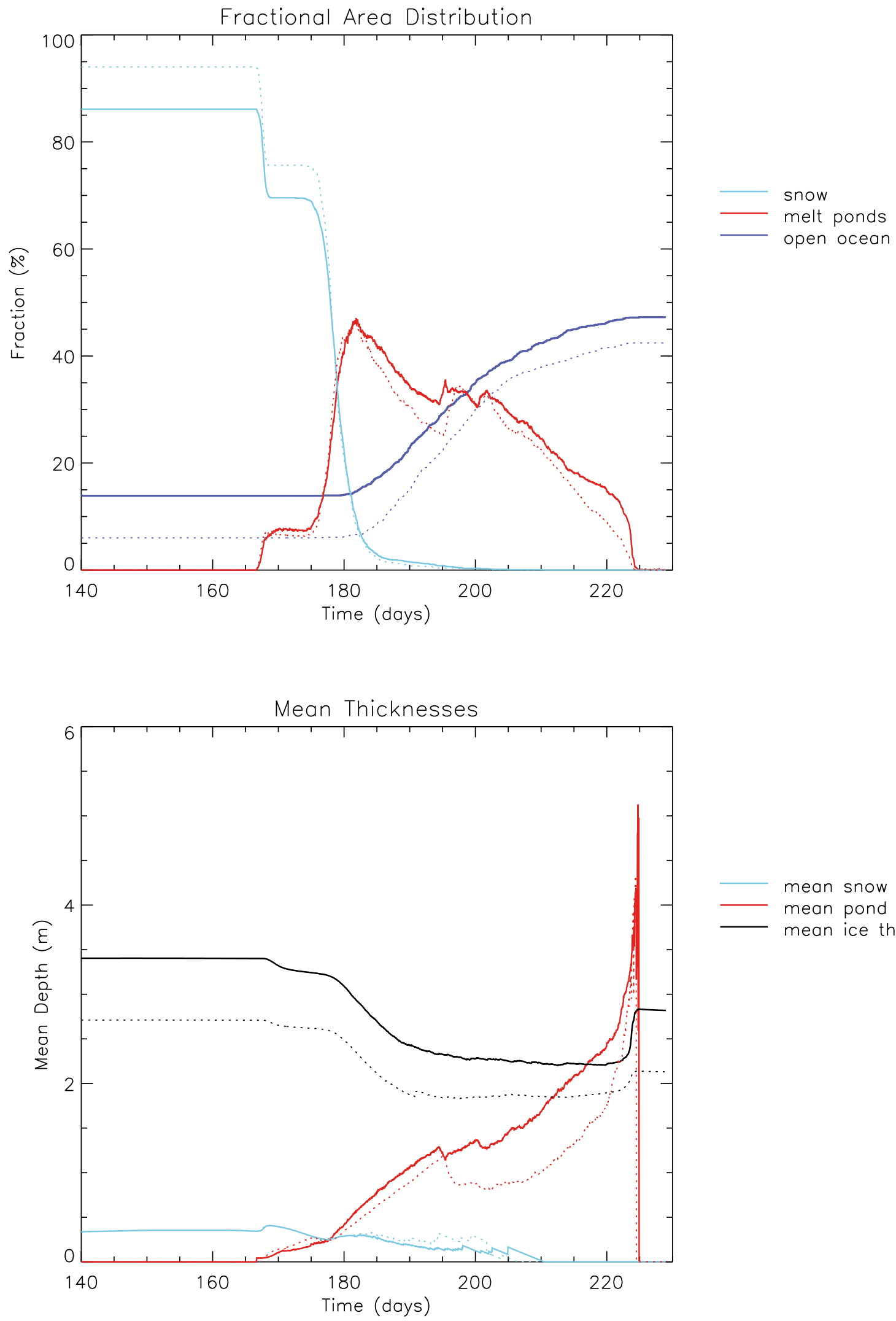

mean snow thickness

mean pond depth

mean ice thickness

Figure 19 

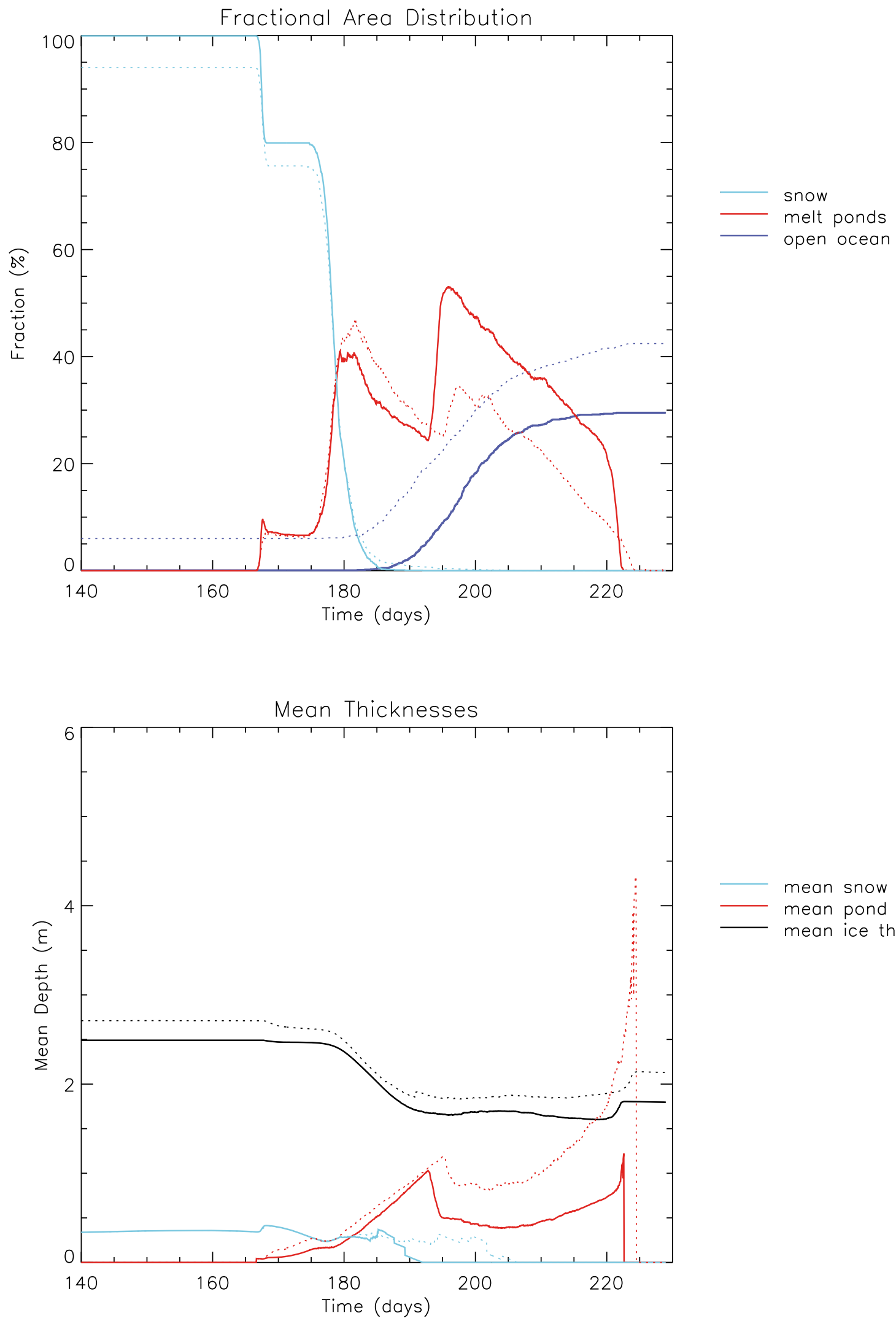

mean snow thickness

mean pond depth

mean ice thickness

Figure 20 


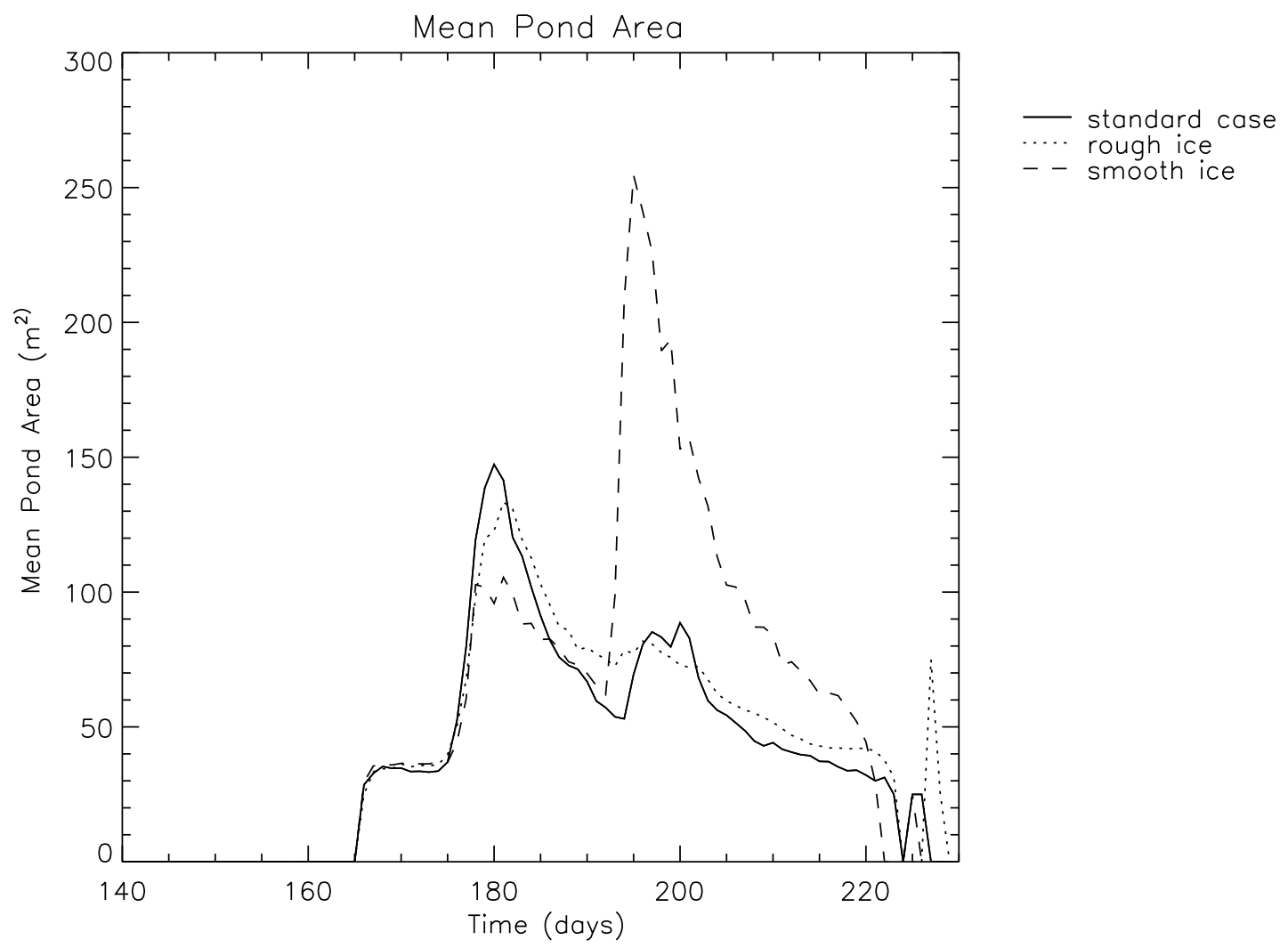

Figure 21. Multiyear ice. Mean individual pond area for the standard case and ice sensitivity studies.

set to zero until the snow cover is removed entirely from a grid cell. We do this because such drainage is believed to be small or nonexistent due to the presence of impermeable ice layers formed from fresh snow melt, following Eicken et al. [2004]. Even in the absence of such impermeable layers, the upper layers of sea ice are sufficiently cold at this time that vertical drainage is very weak. Altering the roughness of the snow surface had the least effect on pond fraction and depth as the surface water was generally guided by ice topography to the only locations where water could collect at the surface and create ponds. The thick snow cover in the first-year ice case provided a large initial volume of surface water so that even though the ice was exposed over a week later than the standard case, there was surface flooding and enhanced melting beneath ponds which resulted in the floe melting almost in its entirety. This behavior has been observed on first-year sea ice [Tucker et al., 1999; Perovich et al., 2002a]. Such surface flooding was not observed in the multiyear ice case due to the deeper depressions in the ice, limiting the horizontal transport of water.

[84] As the roughness of the ice surface increased in both the first-year ice and multiyear ice cases the mean individual pond size decreased, due to the greater variability in ice thickness and presence of topographic lows in ice surface height. This is in accordance with observed differences in pond coverage off Barrow, in north Alaska, and the SHEBA field site reported by Eicken et al. [2004], and other observations [Fetterer and Untersteiner, 1998; Yackel et al., 2000; Tschudi et al., 2001]. There was a limit in roughness beyond which increasing the roughness no longer impacted the fraction of the surface covered in ponds; this is because the horizontal transport of water becomes so limited that ponds are forming at available locations below sea level from local water. The smoothest ice, which was the firstyear ice smooth ice case had very few ponds, particularly early in the season, which is because the ice surface had a mainly positive freeboard so there were few locations for

Figure 20. Multiyear smooth ice case. (top) Variation in the fractional distribution of surface area with time for the smooth ice case, where mean ice thickness is $2.50 \mathrm{~m}$, standard deviation in ice thickness is $0.50 \mathrm{~m}$, mean snow thickness is $0.30 \mathrm{~m}$, and standard deviation in snow thickness is $0.25 \mathrm{~m}$. Fraction of the surface with a snow cover is light blue, fraction of the surface covered with melt ponds is red, and fraction of the surface with no ice cover (open ocean) is dark blue. The dashed lines represent the corresponding values for the standard first-year ice case. (bottom) Change in mean snow depth (light blue), mean pond depth (red), and mean ice thickness (black) with time for the smooth ice case. The dashed lines represent the corresponding values for the standard multiyear ice case. 

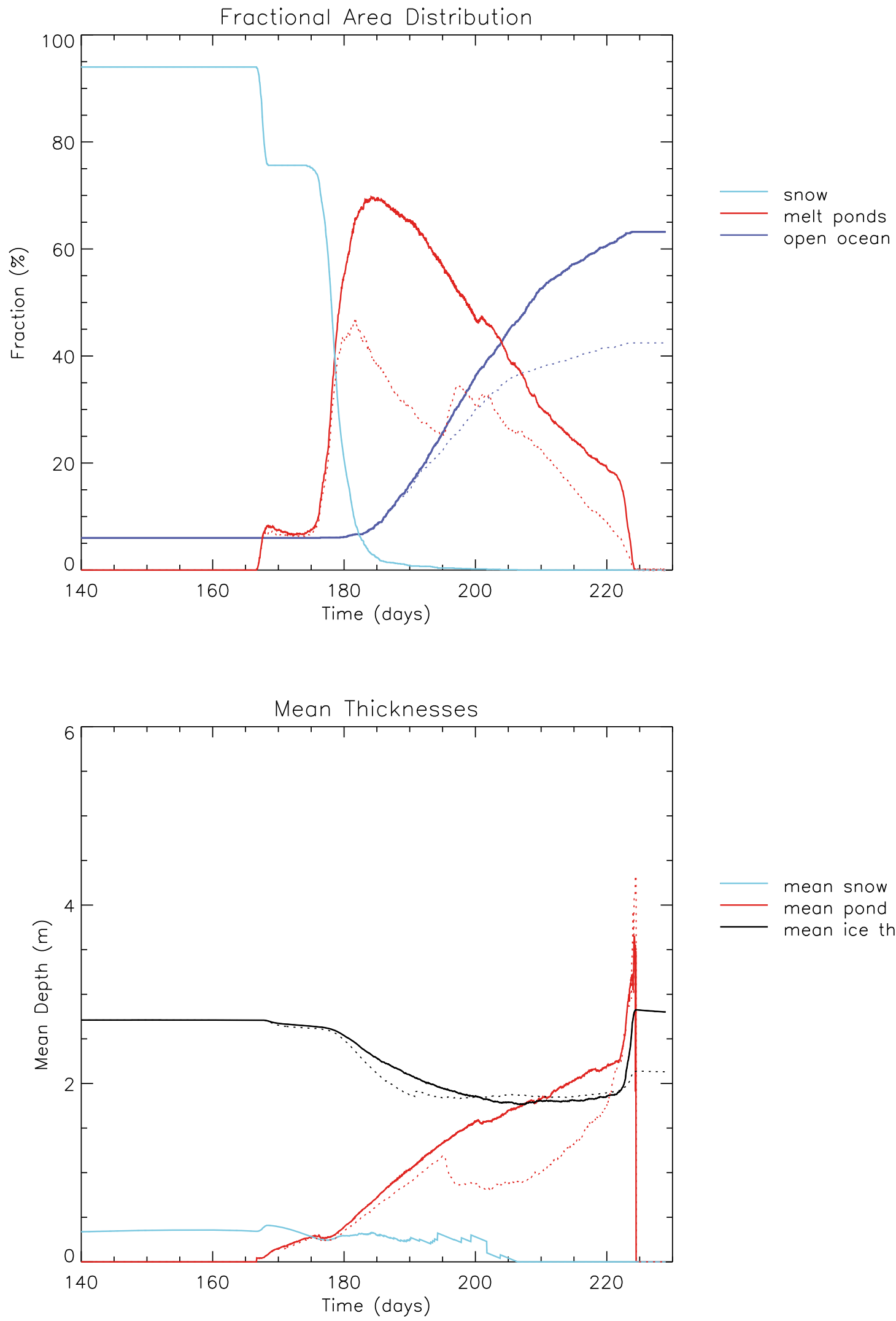

mean snow thickness

mean pond depth

mean ice thickness

Figure 22 
ponds to form. This result agrees with the observation of Eicken et al. [2004] that smooth young ice without a snow cover yields little surface water. Simulations (not shown) of relatively smooth ice in which there is no initial snow cover yield almost no pond coverage. The range of variability in pond fraction was found to be greater on first-year ice than multiyear ice, in agreement with El Naggar et al. [1998] and Eicken et al. [2004]. Note that the ice roughness, rather than thickness, is the primary controller of pond coverage for a given snow cover, as shown by the similarity in pond coverage of rough, first-year ice (section 4.1.2.1) and smooth, multiyear ice (section 4.2.2.2).

[85] Whilst the permeability had a significant impact on the volume of meltwater retained at the surface the impact on pond coverage of the ice topography is also evident. In the first-year ice low-permeability case the flatter ice surface allowed meltwater to spread across the surface, flooding $91 \%$ of the ice with ponds. In the multiyear ice case the rougher surface, with many local minima in ice surface height below sea level, meant that water could not spread across the surface and instead was guided by the topography to the lowest regions, which limited the maximum area covered in ponds to $70 \%, 21 \%$ less than the first-year ice case and with substantially smaller pond areas.

\section{Conclusion and Further Work}

[86] In this paper, we have presented a relatively sophisticated model of the evolution of melt ponds on Arctic sea ice. Our model uses the cellular automaton concept described by Lüthje et al. [2006], with significant improvements, and the one-dimensional vertical heat transport model described by Taylor and Feltham [2004]. The advancements of this model compared to the Lüthje et al. [2006] model are the inclusion of snow topography, a realistic hydraulic balance, calculation of drainage rates based on ice properties and the incorporation of a detailed one-dimensional thermodynamic and radiative model. Lateral and vertical meltwater transport is described with Darcy's law. Thermodynamic processes are modeled using the mushy layer equations in sea ice, heat diffusion equation in snow and using a parameterization of turbulent heat flux in melt ponds, along with a three-layer, two-stream radiation model. The initial ice and snow topographies have been generated using standard statistical methods so that firstyear and multiyear ice can be modeled without having to depend on limited data and the model is forced using SHEBA data. The method used to generate ice and snow topography assumes no correlation between snow depth and ice thickness, or with freeboard and draft thicknesses, this means that there are sometimes deeper depressions in the ice topography than would be expected, a more sophisticated topography model could improve this.

[87] This model captures many of the observed characteristics of melt ponds on first-year and multiyear sea ice. First-year ice had larger, shallower ponds than multiyear ice, although the maximum and mean pond coverage were similar, probably because ponds form in the regions below sea level and the surface area below sea level is similar in both cases.

[88] The results of the standard simulations compare well with general trends of pond evolution observed in the field. The duration of pond coverage, pond area and ice ablation compare well in both first-year ice and multiyear ice cases. Whilst pond fraction in the modeled multiyear ice case appears higher than many of the multiyear ice observed values, it compares well with the level multiyear ice values of Eicken et al. [2002], which is the ice topography that we aimed to simulate.

[89] The albedo is calculated for each grid cell from a two-stream radiative model and depends upon the presence of wet or dry snow, and the presence and depth of meltwater, as well as the thickness of the underlying ice, following Taylor and Feltham [2004]. The average of the albedo in all grid cells, including cells containing open ocean, is calculated to determine the area-averaged albedo. Figures 25-30 show the evolution of the area-averaged albedo for the different scenarios presented in this paper. The area-averaged surface albedo of the summer ice cover is largely determined by the area of the sea ice covered in melt ponds and the open ocean fraction. The depth of the melt ponds plays a relatively minor role in determining the areaaveraged albedo. Observed mean albedo values are consistently lower than modeled mean albedo values which suggests that calculation of albedo in individual cells in the model needs to be modified. The radiative model is relatively simple, treating each component (snow, sea ice, melt pond) as one optical layer with averaged optical properties. It is likely that a more sophisticated treatment of the optical properties would yield improvements in predicted albedo. There is particular uncertainty in the value and evolution of the optical scattering coefficient of ice beneath melt ponds [see Taylor and Feltham, 2004]. Careful measurements of the transmission and absorption of solar radiation of ponded ice would help improve the model. In addition, multiyear ice contains more air bubbles that first-year ice, the surface layer of multiyear ice is drained and bubbly before the onset of melt, whereas first-year ice has more brine pockets which scatter less radiation than air bubbles. The decreased scattering in first-year ice causes more radiation to be absorbed into the ice and thus more melting.

[90] Generated ice topographies with the same initial mean thickness, standard deviation, and range yielded near

Figure 22. Multiyear ice, low-permeability case. (top) Variation in the fractional distribution of surface area with time for the low-permeability case, where mean ice thickness is $2.50 \mathrm{~m}$, standard deviation in ice thickness is $1.10 \mathrm{~m}$, mean snow thickness is $0.30 \mathrm{~m}$, and standard deviation in snow thickness is $0.25 \mathrm{~m}$. Fraction of the surface with a snow cover is light blue, fraction of the surface covered with melt ponds is red, and fraction of the surface with no ice cover (open ocean) is dark blue. The dashed lines represent the corresponding values for the standard multiyear ice case. (bottom) Change in mean snow depth (light blue), mean pond depth (red), and mean ice thickness (black) with time for the low-permeability case. The dashed lines represent the corresponding values for the standard multiyear ice case. 

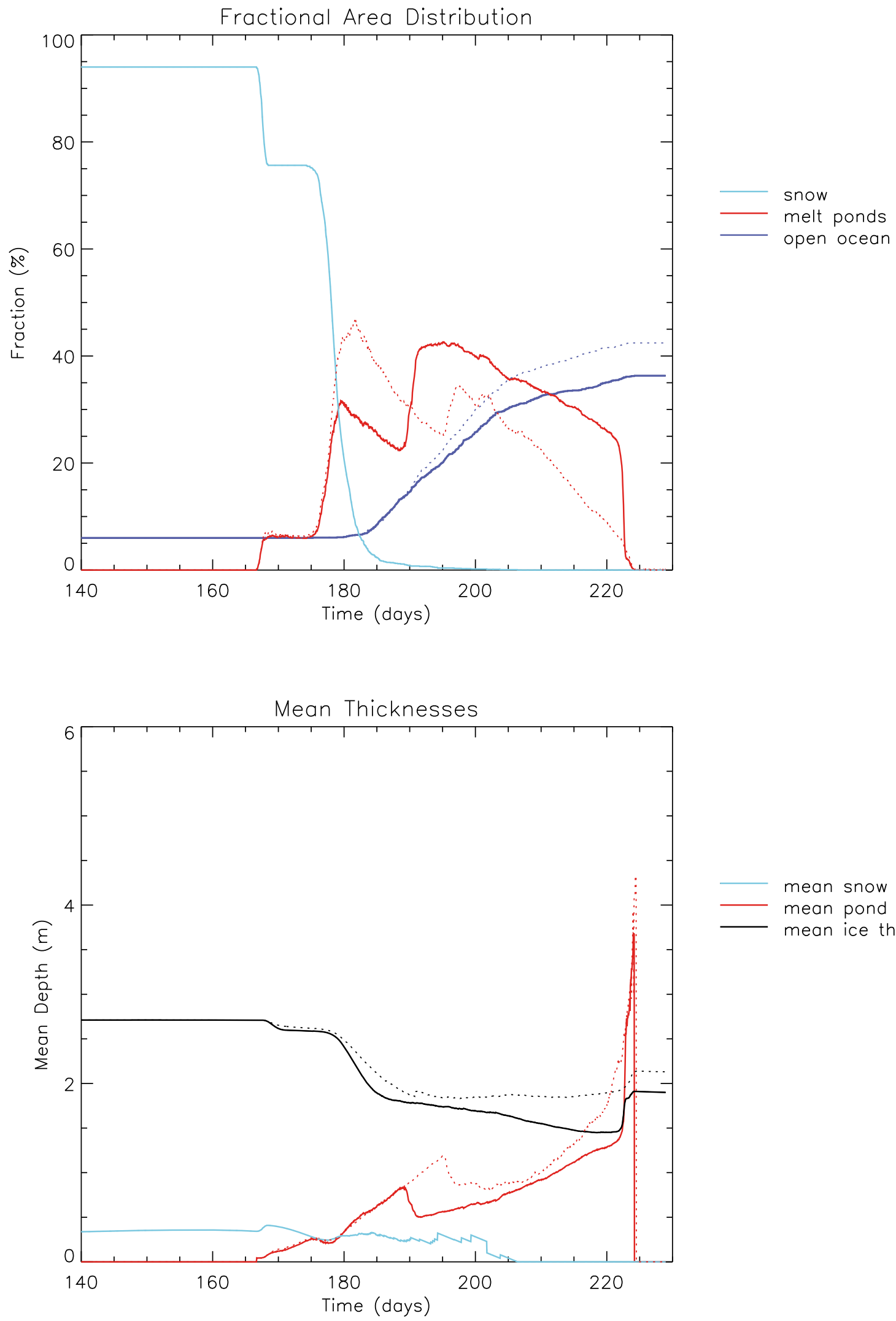

mean snow thickness

mean pond depth

mean ice thickness

Figure 23 


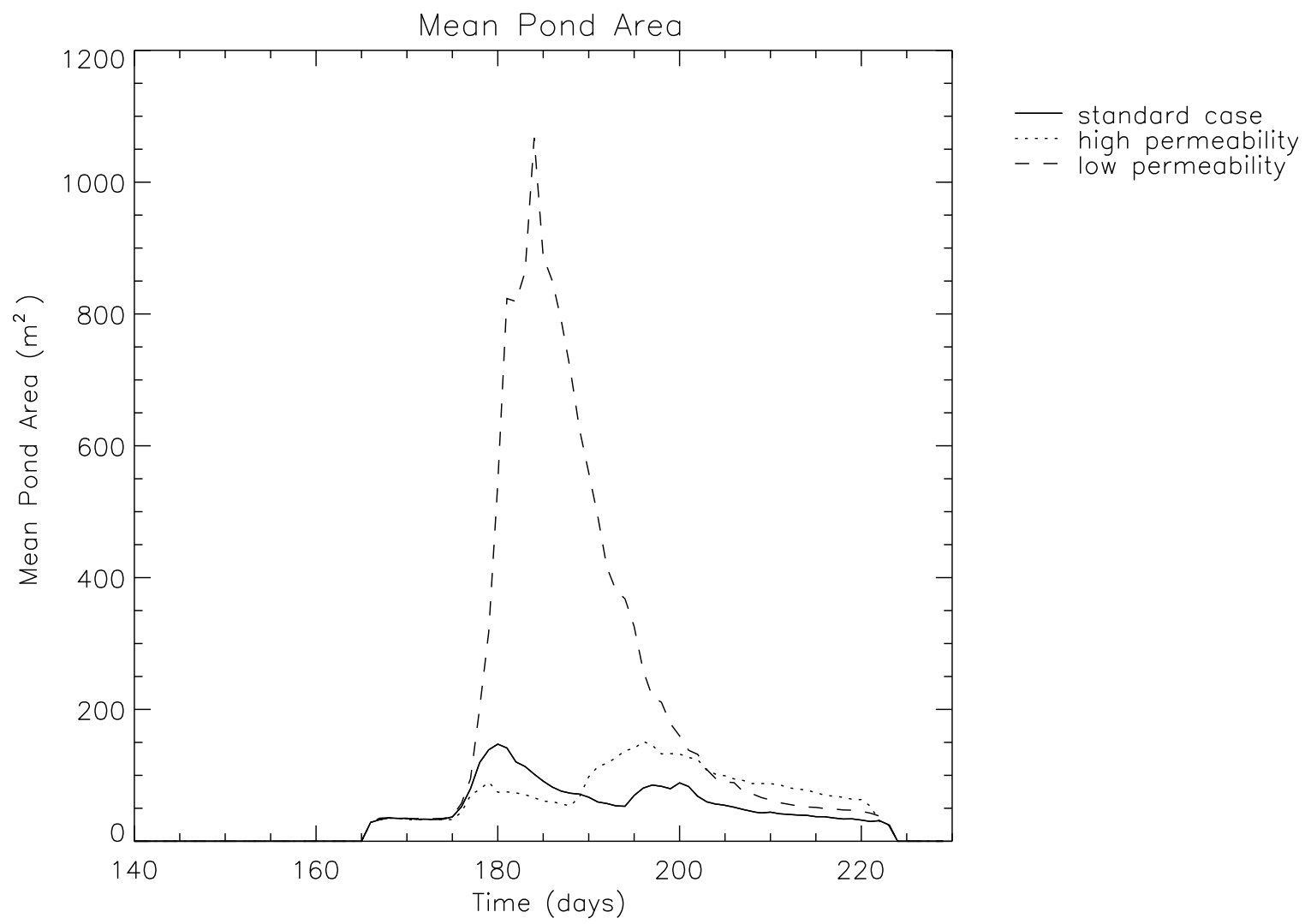

Figure 24. Multiyear ice. Mean individual pond area for the standard case and vertical permeability sensitivity studies.

identical patterns of pond coverage, with some further work this could provide a useful insight into the development of a melt pond parameterization in GCMs.

[91] Additional areas of model development should include more accurate representation of the hydraulic processes governing meltwater transport, including surface flow in "rivers" recently observed (C. Polashenski and D. Perovich, personal communication, 2010), and the representation of melt pond side wall melting [Skyllingstad et al., 2009]. Since the underlying ice topography plays such a central role in determining the location and extent of pond formation, detailed measurements of topography, in conjunction with observations of the pond evolution and surface forcing, will enable a stricter test of the melt-pond-sea-ice model.

[92] While the melt-pond-sea-ice model does not attempt to replicate diurnal variation and short-lived effects of rainfall, the sensitivity studies presented in this paper reveal that the melt-pond-sea-ice model captures the main observed features in the evolution of melt ponds. The sensitivity studies have allowed us to explore systematically the impact on pond coverage and ice and snow ablation of variations in snow and ice topography and uncertainty in ice permeability, and the results found are in general agreement with inferences drawn from observations. Although the snow topography has a local and short-term impact on the pattern of melt pond evolution, it was found that mean snow thickness was a greater predictor of the pond coverage throughout the melt season. Underlying ice topography was found to guide the flow of snow melt to the locations of pond formation.

[93] We found that thick snow covers on first-year ice resulted in the greatest area fraction of melt ponds and thus the lowest area-averaged albedos. Although the total area of

Figure 23. Multiyear ice, high-permeability case. (top) Variation in the fractional distribution of surface area with time for the high-permeability case, where mean ice thickness is $2.50 \mathrm{~m}$, standard deviation in ice thickness if $1.10 \mathrm{~m}$, mean snow thickness is $0.30 \mathrm{~m}$, and standard deviation in snow thickness is $0.25 \mathrm{~m}$. Fraction of the surface with a snow cover is light blue, fraction of the surface covered with melt ponds is red, and fraction of the surface with no ice cover (open ocean) is dark blue. The dashed lines represent the corresponding values for the standard multiyear ice case. (bottom) Change in mean snow depth (light blue), mean pond depth (red), and mean ice thickness (black) with time for the high-permeability case. The dashed lines represent the corresponding values for the standard multiyear ice case. 

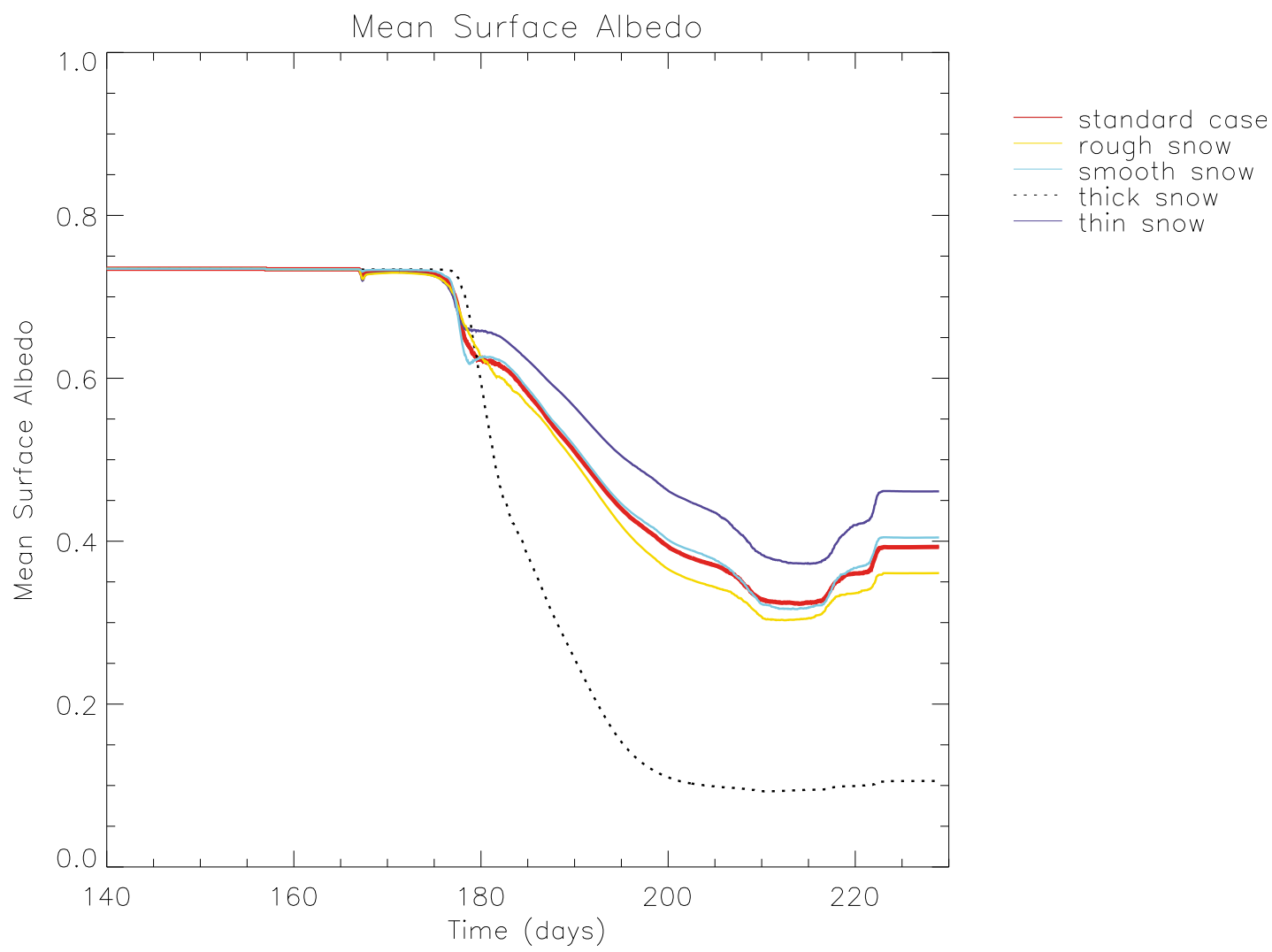

Figure 25. First-year ice. Change of area-averaged surface albedo with time for the standard case and snow sensitivity studies.

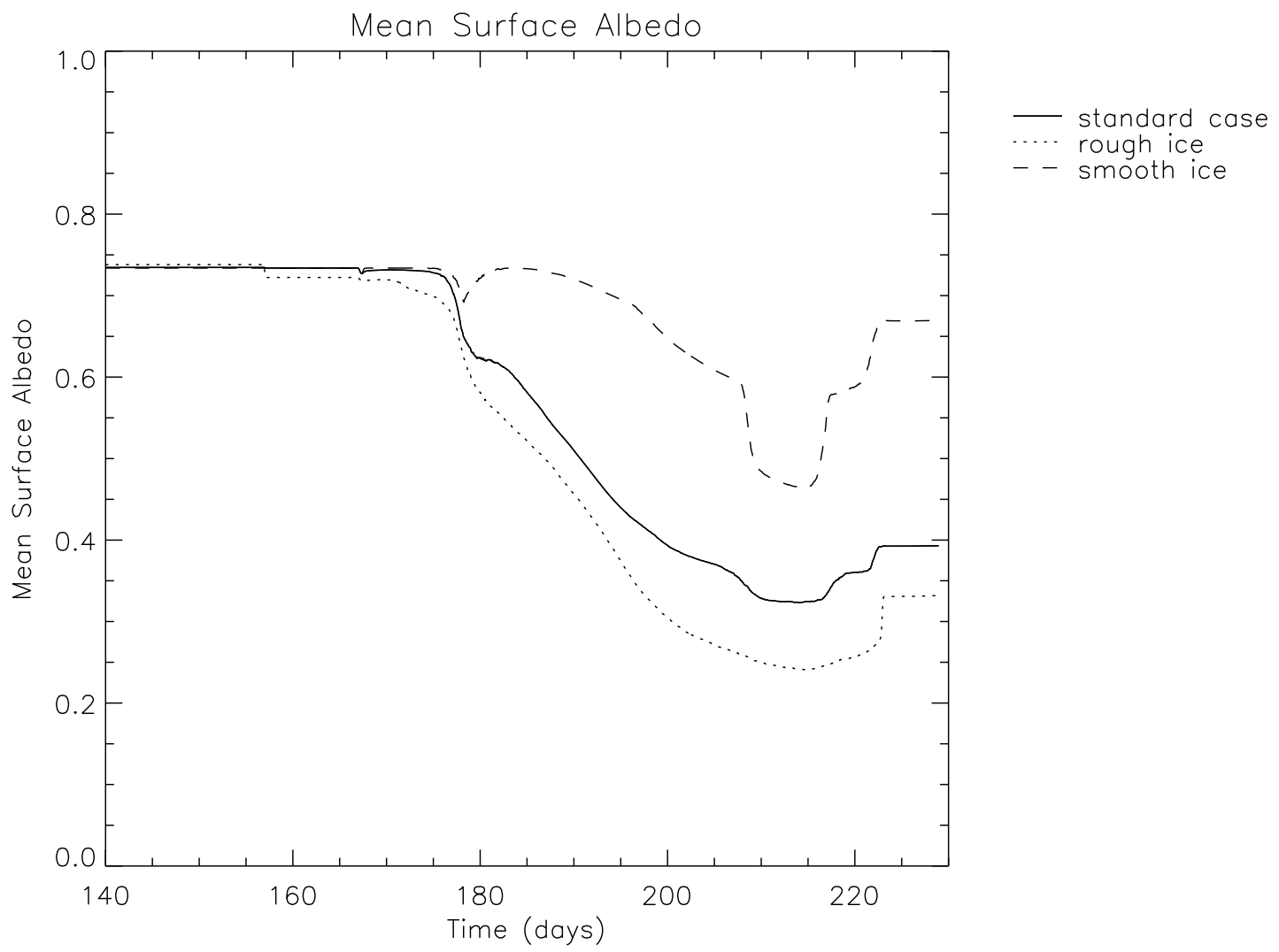

Figure 26. First-year ice case. Change of area-averaged surface albedo with time for the standard case (solid line) and ice sensitivity studies. 


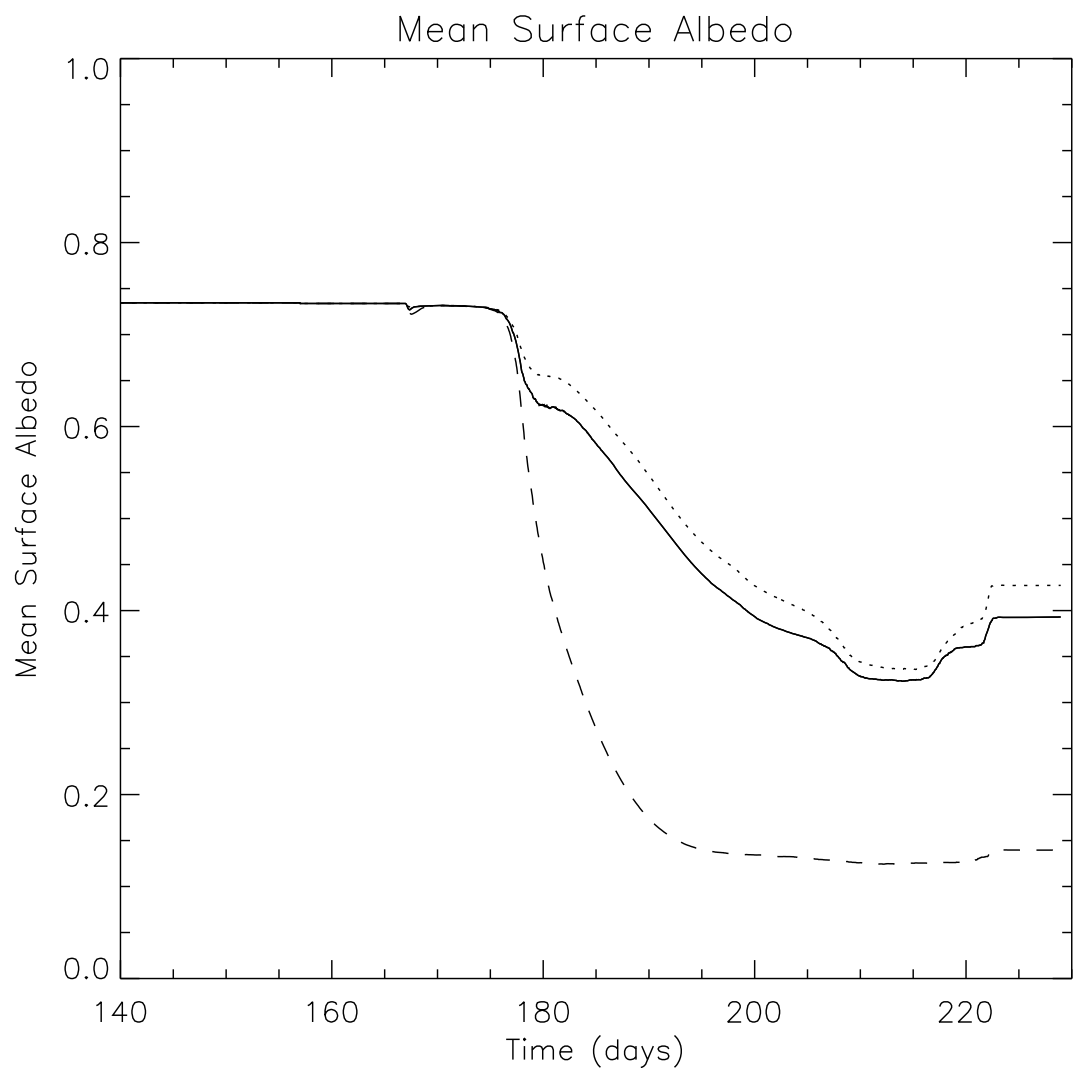

- standard case .... high permeability - low permeability

Figure 27. First-year ice case. Change of area-averaged surface albedo with time for the standard case and permeability sensitivity studies.

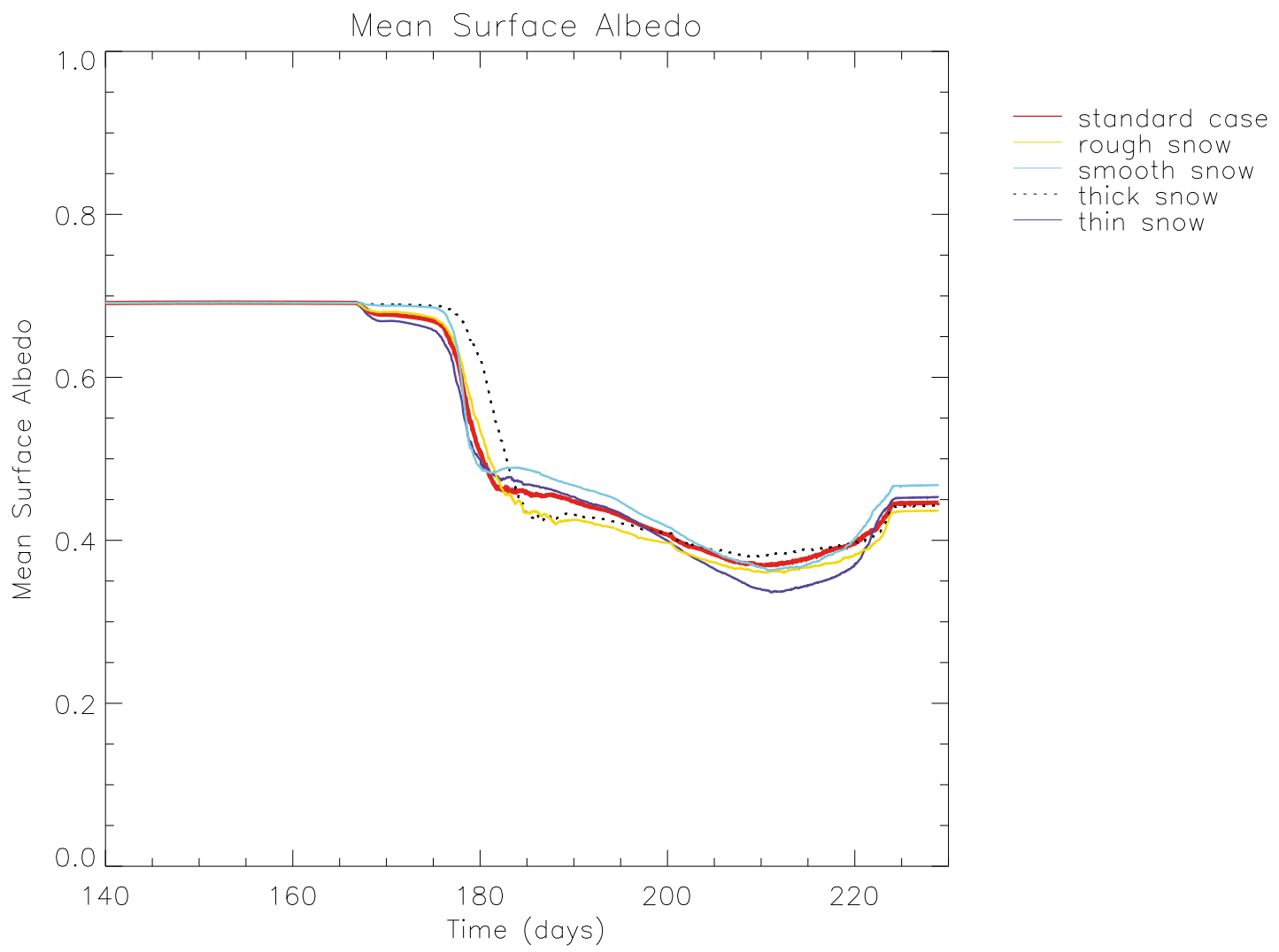

Figure 28. Multiyear ice. Change of area-averaged surface albedo with time for the standard case and snow sensitivity studies. 


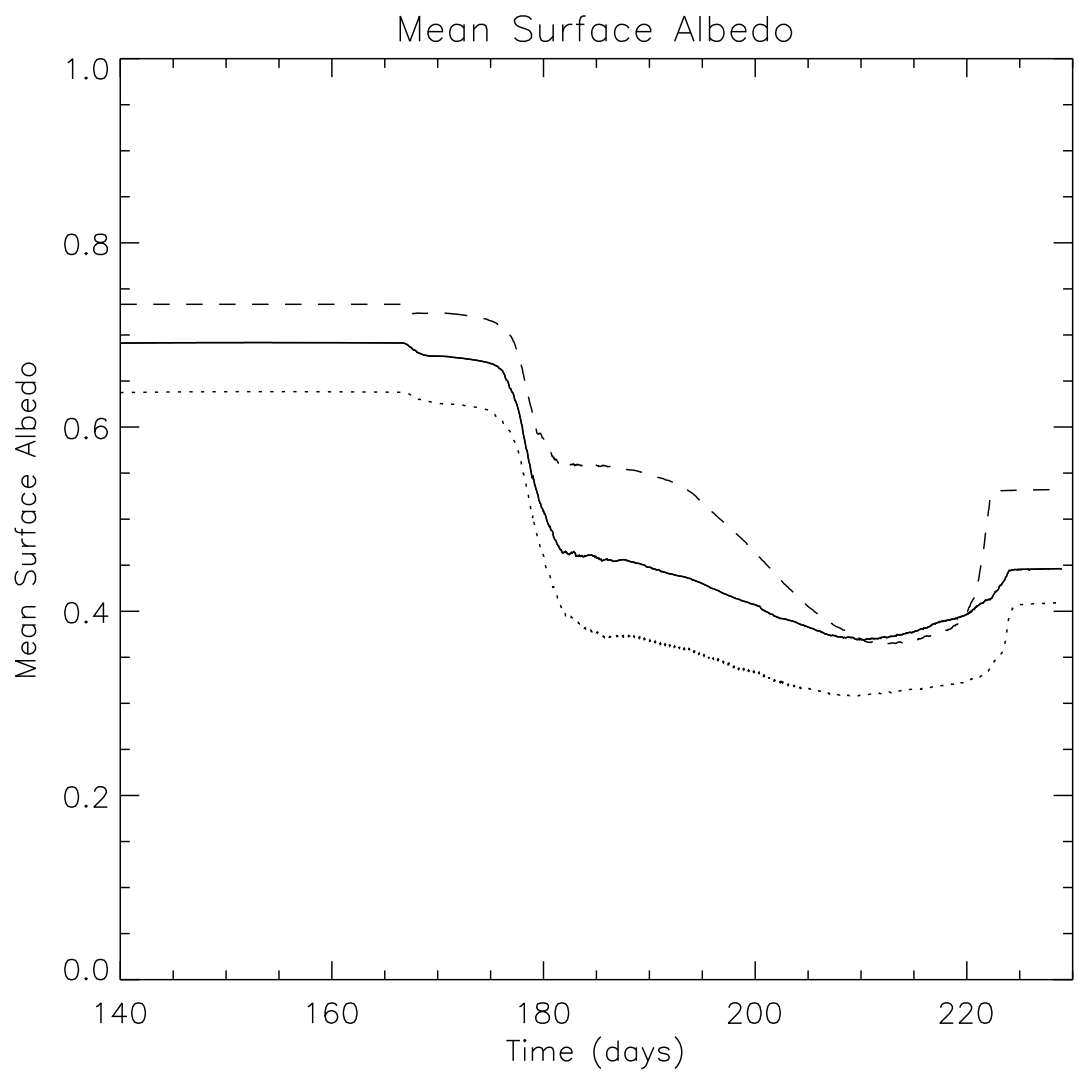

- standard case

.... rough ice

- smooth ice

Figure 29. Multiyear ice case. Change of area-averaged surface albedo with time for the standard case and ice sensitivity studies.

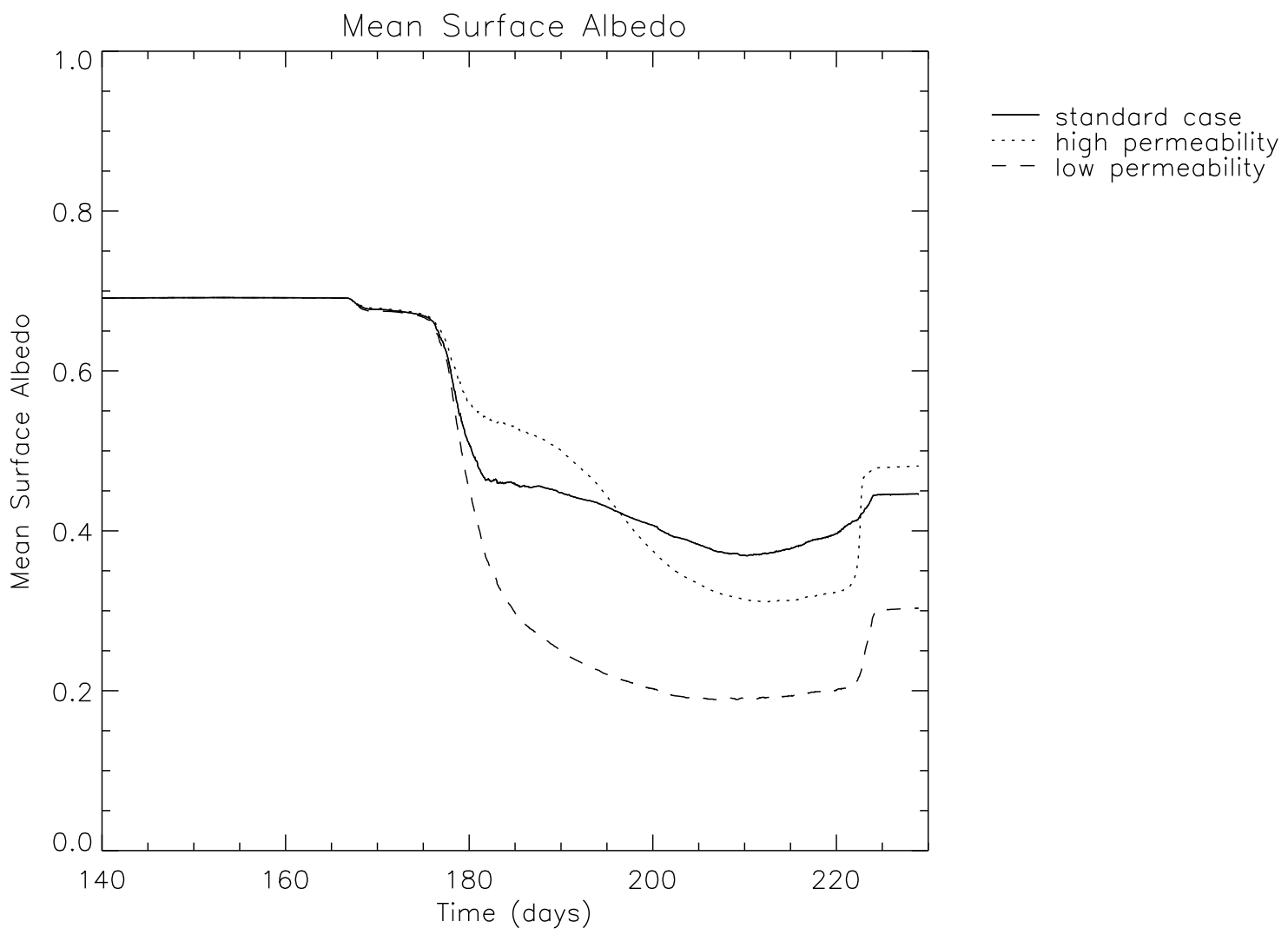

Figure 30. Multiyear ice case. Change of area-averaged surface albedo with time for the standard case and vertical permeability sensitivity studies. 
sea ice is reducing, the relative fraction of first-year ice is increasing [Cavalieri et al., 2003]. Our simulations show that melt ponds cover a greater fraction of first-year ice than multiyear ice, suggesting that melt ponds will become increasingly significant in controlling the melting of Arctic sea ice.

[94] Acknowledgments. D.L.F. acknowledges financial support made available through the award of a research prize by the Leverhulme Trust.

\section{References}

Cavalieri, D. J., C. L. Parkinson, and K. Y. Vinnikov (2003), 30-Year satellite record reveals contrasting Arctic and Antarctic decadal sea ice variability, Geophys. Res. Lett., 30(18), 1970, doi:10.1029/2003GL018031.

Derksen, C., J. Piwowar, and E. LeDrew (1997), Sea-ice melt-pond fraction as determined from low level aerial photographs, Arct. Alp. Res., 29(3), 345-351.

Ebert, E. E., J. L. Schramm, and J. A. Curry (1995), Disposition of solar radiation in sea ice and the upper ocean, J. Geophys. Res., 100(C8), 15,965-15,975.

Eicken, H., H. R. Krouse, D. Kadko, and D. K. Perovich (2002), Tracer studies of pathways and rates of meltwater transport through Arctic summer sea ice, J. Geophys. Res., 107(C10), 8046, doi:10.1029/ 2000JC000583.

Eicken, H., T. C. Grenfell, D. K. Perovich, J. A. Richter-Menge, and K. Frey (2004), Hydraulic controls of summer Arctic pack ice albedo, J. Geophys. Res., 109, C08007, doi:10.1029/2003JC001989.

El Naggar, S., C. Garrity, and R. O. Rameseier (1998), The modeling of sea ice melt-water ponds for the high Arctic using an airborne line scan camera, and applied to the satellite special sensor microwave/imager (SSM/I), J. Remote Sens., 19(12), 2373-2394.

Feltham, D. L., N. Untersteiner, J. S. Wettlaufer, and M. G. Worster (2006), Sea ice is a mushy layer, Geophys. Res. Lett., 33, L14501, doi:10.1029/ 2006GL026290.

Fetterer, F., and N. Untersteiner (1998), Observations of melt ponds on Arctic sea ice, J. Geophys. Res., 103(C11), 24,821-24,835.

Flocco, D., and D. L. Feltham (2007), A continuum model of melt pond evolution on Arctic sea ice, J. Geophys. Res., 112, C08016, doi:10.1029/ 2006JC003836.

Flocco, D., D. L. Feltham, and A. K. Turner (2010), Incorporation of a physically based melt pond scheme into the sea ice component of a climate model, J. Geophys. Res., 115, C08012, doi:10.1029/2009JC005568.

Freitag, J., and H. Eicken (2003), Meltwater circulation and permeability of Arctic summer sea ice derived from hydrological field experiments, J. Glaciol., 49(166), 349-358.

Giles, K. A., S. W. Laxon, and A. L. Ridout (2008), Circumpolar thinning of Arctic sea ice following the 2007 record ice extent minimum, Geophys. Res. Lett., 35, L22502, doi:10.1029/2008GL035710.

Golden, K. M., H. Eicken, A. L. Heaton, J. Miner, D. J. Pringle, and J. Zhu (2007), Thermal evolution of permeability and microstructure in sea ice, Geophys. Res. Lett. 34, L16501, doi:10.1029/2007GL030447.

Hanesiak, J. M., D. G. Barber, R. A. De Abreu, and J. J. Yackel (2001), Local and regional albedo observations of Arctic first-year sea ice during melt ponding, J. Geophys. Res., 106(C1), 1005-1016.

Laxon, S., N. Peacock, and D. Smith (2003), High interannual variability of sea ice thickness in the Arctic region, Nature, 425(6961), 947-950.
Light, B., T. C. Grenfell, and D. K. Perovich (2008), Transmission and absorption of solar radiation by Arctic sea ice during the melt season, J. Geophys. Res. 113, C03023, doi:10.1029/2006JC003977.

Lüthje, M., D. L. Feltham, P. D. Taylor, and M. G. Worster (2006), Modeling the summertime evolution of sea-ice melt ponds, J. Geophys. Res. 111, C02001, doi:10.1029/2004JC002818.

Maykut, G. A., and N. Untersteiner (1971), Some results from a timedependent thermodynamic model of sea ice, J. Geophys. Res., 76(6), $1550-1575$.

Pedersen, C. A., M. Roeckner, M. Lüthje, and J. Winther (2009), A new sea ice albedo scheme including melt ponds for ECHAM5 general circulation model, J. Geophys. Res., 114, D08101, doi:10.1029/2008JD010440.

Perovich, D. K. (1990), Theoretical estimates of light reflection and transmission by spatially complex and temporally varying sea ice covers, J. Geophys. Res., 95(C6), 9557-9567.

Perovich, D. K. (1996), The Optical Properties of Sea Ice, Monogr. Ser., vol. 96-1, Cold Reg. Res. and Eng. Lab., Hanover, N. H.

Perovich, D. K., T. C. Grenfell, B. Light, J. A. Richter-Menge, M. Sturm, W. B. Tucker, H. Eicken, G. A. Maykut, and B. Elder (1999), SHEBA: Snow and ice studies, version 1.0, report, Cold Reg. Res. and Eng. Lab., Hanover, N. H.

Perovich, D. K., W. B. Tucker, and K. A. Ligett (2002a), Aerial observations of the evolution of ice surface conditions during summer, J. Geophys. Res., 107(C10), 8048, doi:10.1029/2000JC000449.

Perovich, D. K., T. C. Grenfell, B. Light, and P. V. Hobbs (2002b), Seasonal evolution of the albedo of multiyear Arctic sea ice, J. Geophys. Res., 107(C10), 8044, doi:10.1029/2000JC000438.

Perovich, D. K., T. C. Grenfell, J. A. Richter-Menge, B. Light, W. B. Tucker III, and H. Eicken (2003), Thin and thinner: Sea ice mass balance measurements during SHEBA, J. Geophys. Res. 108(C3), 8050 doi:10.1029/2001JC001079.

Rothrock, D. A., Y. Yu, and G. A. Maykut (1999), Thinning of the Arctic sea-ice cover, Geophys. Res. Lett., 26(23), 3469-3472.

Scott, F. (2009), Modelling the evolution of Artic melt ponds, Ph.D. thesis, Univ. Coll. London, London.

Skyllingstad, E. D., C. A. Paulson, and D. Perovich (2009), Simulation of melt pond evolution on level ice, J. Geophys. Res., 114, C12019, doi:10.1029/2009JC005363.

Solomon, S., D. Quin, M. Manning, Z. Chen, M. Marquis, K. B. Averyt, M. Tignor, and H. L. Miller (Eds.) (2007), Climate Change 2007: The Physical Science Basis: Working Group I Contribution to the Fourth Assessment Report of the Intergovernmental Panel on Climate Change, Cambridge Univ. Press, New York.

Sturm, M., J. Holmgren, and D. K. Perovich (2002), Winter snow cover on the sea ice of the Arctic Ocean at the Surface Heat Budget of the Arctic Ocean (SHEBA): Temporal evolution and spatital variability, J. Geophys. Res., 107(C10), 8047, doi:10.1029/2000JC000400.

Taylor, P. D., and D. L. Feltham (2004), A model of melt pond evolution on sea ice, J. Geophys. Res., 109, C12007, doi:10.1029/2004JC002361.

Tschudi, M. A., J. A. Curry, and J. A. Malanik (2001), Airborne observations of summertime surface features and their effect on surface albedo during FIRE/SHEBA, J. Geophys. Res., 106(D14), 15,335-15,344.

Tucker, W. B., A. J. Gow, D. A. Meese, H. W. Bosworth, and E. Reimnitz (1999), Physical characteristics of summer sea ice across the Arctic Ocean, J. Geophys. Res., 104(C1), 1489-1504.

Yackel, J. J., D. G. Barber, and J. M. Hanesiak (2000), Melt ponds on sea ice in the Canadian Archipelago: 1. Variability in morphological and radiative properties, J. Geophys. Res., 105(C9), 22,049-22,060.

D. L. Feltham and F. Scott, Centre for Polar Observation and Modelling, Department of Earth Sciences, University College London, Gower Street, London WC1E 6BT, UK. (dlf@cpom.ucl.ac.uk; fs@cpom.ucl.ac.uk) 